AROUEOLOGÍA Y SOCIEDAD

№ $25,2012: 303-326$

ISSN: $0254-8062$

RECIBIDO: AGOSTO DE 2012 ACEPTADO: OCTUBRE DE 2012

\title{
NUEVAS INVESTIGACIONES EN HUAYURCO: RESULTADOS INICIALES DE LAS EXCAVACIONES DE UN SITIO DE LA CEJA DE SELVA DE LOS ANDES PERUANOS*
}

\author{
RYAN CLASBY \\ UNIVERSIDAD DEYALE \\ ryan.clasby@yale.eduxxx \\ JORGE MENESES BARTRA \\ PROYECTO ARQUEOLÓGICO HUACA DE LA LUNA \\ nicholas_81@hotmail.com
}

\section{RESUMEN}

Descubierto en 1961 por Pedro Rojas $(1961,1985)$ como parte de lo que fue la expedición de Tello al Marañón, Huayurco fue uno de los primeros sitios en los Andes peruanos orientales en ser excavado. La recuperación de ofrendas exóticas además de múltiples cuencos líticos finamente manufacturados permitieron a Rojas y Donald Lathrap (1970: 108-109) sugerir que Huayurco fue un centro importante de intercambio durante el Horizonte Temprano (900-200 a.C.), contribuyendo a facilitar la interacción interregional entre la costa del Pacífico, las sierras y las tierras bajas de la Amazonia. En el año 2010, llevamos a cabo excavaciones en Huayurco para examinar esta hipótesis. Los resultados preliminares de la prospección y excavación confirman las relaciones a larga distancia y muestran que el sitio es mucho más grande de lo que se registró originalmente, con una larga y compleja historia ocupacional.

Palabras Clave: Huayurco, ceja de selva, Jaén, Horizonte Temprano, periodo Intermedio Temprano.

\begin{abstract}
Discovered in 1961 by Pedro Rojas $(1961,1985)$ as part of follow-up research to Tello's Marañon expedition, Huayurco was one of the first sites in the eastern Peruvian Andes to be formally excavated. The recovery of exotic offerings in addition to multiple finely crafted stone bowls led Rojas and Donald Lathrap (1970: 108-109) to suggest that Huayurco was an important center of exchange during the Early Horizon (900-200 B.C), helping to facilitate interregional interaction between the Pacific coast, highlands and Amazonian lowlands. In 2010, we conducted excavations at Huayurco to examine this hypothesis. Preliminary survey and excavation results confirm Huayurco's long distance relationships and show that the site is much larger than originally recorded with a long and complex occupational history.
\end{abstract}

KEYwords: Huayurco, cloud forest, Jaén, Early Horizon, Early Intermediate period.

* Traducido por Víctor Falcón Huayta. 


\section{INTRODUCCIÓN}

Este artículo presenta los resultados preliminares de las investigaciones arqueológicas en Huayurco, un sitio ubicado en las laderas del noreste de los Andes peruanos. Descubierto por Pedro Rojas (1961, 1985) en 1961, Huayurco fue unos de los primeros sitios en la ceja de selva en ser excavado. El descubrimiento de productos malacológicos del mar y una industria de platos de piedra realizado por Rojas y Donald Lathrap (1970: 108-109) sugiere que Huayurco fue un centro importante de intercambio en la parte superior de Amazonia durante el Horizonte Temprano (900-200 B.C), ayudando a facilitar interacción interregional entre la costa pacífica, las sierras, y la selva baja.

Desde su descubrimiento inicial en 1961, Huayurco ha mantenido una posición privilegiada en la literatura arqueológica andina (véase Burger 1992: 218-219; Lathrap 1970; Zeidler 2008), como un sitio de potencial importancia, no sólo para entender las relaciones interregionales entre los Andes y la Amazonia sino también para reconstruir el tipo de sociedades que se desarrollaron internamente en la ceja de selva. Antes que simplemente una zona de amortiguamiento o área de explotación para sociedades andinas y amazónicas, las excavaciones en Huayurco sugieren que las sociedades complejas se establecieron muy temprano en ciertas partes de la ceja de selva, completamente comprometidas en complejas redes de intercambio interregional.

De muchas maneras, Huayurco aún continuó destacándose en la literatura actual que demuestran los problemas más importantes de la arqueología de la ceja de selva. A pesar de que la investigación de Rojas se dio hace 50 años, muchas áreas de la ceja de selva permanecen arqueológicamente desconocidas. Igualmente, en aquellas áreas donde se han realizado muchas investigaciones tales como Jaén (Atwood 2011; Miasta 1979; Olivera 1998; Sandoval 2012; Shady 1973, 1987, 1999; Shady y Rosas 1979; Yamamoto 2008), sur de Ecuador (Valdez 2008) o Chachapoyas (Church 1996; Church y von Hagen 2008; Ruiz 2010; Schjellerup 2005), los investigadores sólo están comenzando a entender las culturas que se desarrollaron en aquellas regiones. De 2007-2010, conducimos una prospección y excavación para probar la hipótesis de Rojas y Lathrap, es decir validar que efectivamente Huayurco fue un centro importante de interacción interregional entre la costa, sierras, y selva baja. Para evaluar esta situación, la investigación fue enfocada de la siguiente manera: 1. Construir una cronología por el sitio y la región de Jaén; 2. Definir la función y tipo de uso del sitio de Huayurco; 3. Entender la naturaleza y rango de las relaciones interregionales en las que Huayurco participó; 4. Investigar como las relaciones cambiaron al pasar de los años y su impacto sobre la organización sociopolítica de Huayurco.

\section{LA Región de JaÉn y la CEJA de SElVA de los Andes PeRuanos}

La ceja de selva de los Andes peruanos ha sido considerada mayormente de poca importancia en los desarrollos culturales prehistóricos que se dieron en los ámbitos de la sierra y costa adyacentes. Debido a su geografía, una banda estrecha de floresta de montaña tropical caracterizada por laderas abruptas, abundantes lluvias y densa vegetación (Pulgar 1972; Raymond 1988), la ceja de selva se consideró como un medio ambiente de limitada capacidad para generar asentamientos permanentes, grandes poblaciones y sociedades complejas (Steward 1948: 507-508; véase Kauffman Doig 2003; Raymond 1988; Taylor 1999: 196-197). Las limitaciones impuestas por el ambiente de montaña habrían creado una barrera geopolítica - «tierra de nadie»- que detuvo la expansión de las interacciones e intercambio, dejando a las civilizaciones de los Andes en un desarrollo independiente de sus contrapartes de las tierras tropicales bajas.

Sin embargo, recientes investigaciones en la ceja de selva, han comenzado a revertir esta falsa premisa de la floresta tropical. La ceja de selva no sólo es considerablemente diversa desde una perspectiva ecológica con un amplio rango de microclimas formados por las precipitaciones locales, altitud y tipos de suelos (Bush et al. 2011; Gentry 1988; Raymond 1988) sino que ciertas áreas han sido intensamente pobladas en el curso de la prehistoria andina, en algunos casos con habitantes locales 
jugando un rol crítico en facilitar el intercambio económico e ideológico entre la costa-sierra y las tierras bajas de la Amazonia (véase Alconini 2004; Burger 1984, 2003; Church 1996; Church y von Hagen 2008; DeBoer 2003; Guffroy 2008; Isbell 1974; Lathrap 1970; Raymond 1988; Shady 1999; Taylor 1999; Valdez 2008; Yamamoto 2007, 2008; Zeidler 2008). Antes que una zona aislada culturalmente, los documentos etnohistóricos sugieren que algunas poblaciones de la ceja de selva mantuvieron estructuras sociopolíticas complejas y establecieron reiterados contactos con la gente de los Andes, frecuentemente involucrados en redes de intercambio entre sociedades de la sierra y otras de tierras bajas (Raymond 1988; Taylor 1999).

El concepto de la ceja de selva como un conducto antes que una barrera es tan importante como aquella que las sociedades no se desarrollan aisladamente sino que su conformación tiene influencias externas que se dan como resultado de patrones de interacción con culturas vecinas (Kohl 2008; Wolf 1982, 1984). Así, los desarrollos culturales en la sierra y costa están intrínsecamente vinculados a las relaciones que se establecieron con las personas de la floresta tropical. Por ejemplo, la mayor parte de la iconografía en la costa y sierra durante el periodo Inicial (1800-900 a.C.) y el Horizonte Temprano (900-200 a.C.) muestran imágenes de plantas y animales de la floresta tropical tales como mandioca, el jaguar, el águila arpía y el caimán (Burger 1992; Lathrap 1970, 1971; Tello 1960). El predominio de estas imágenes en la cerámica, la lapidaria, el metal y otros medios sugieren que la cosmología de las sociedades de los Andes Centrales durante estos periodos tempranos procede significativamente de la floresta tropical lluviosa, probablemente indicando una cercana interacción interregional. Esto es sumamente importante debido a que estos periodos de tiempo están asociados con el surgimiento de las sociedades complejas en las costas central y norte, así como, en la sierra norte del Perú. Estas interacciones influenciaron en el desarrollo cultural en los Andes Centrales y han sido necesarias para entender los procesos históricos más extensos relacionados a la civilización andina. Situadas entre la sierra y las tierras bajas tropicales, las poblaciones de la ceja de selva posiblemente jugaron un papel clave en facilitar la interacción entre las sociedades de ambas áreas.

Un área de posible importancia para entender las tempranas redes de interacción interregional y que ha recibido considerable grado de atención en años recientes es la región de Jaén al noreste del Perú, cerca al límite con Ecuador (Fig. 1). Jaén está localizado entre dos zonas ecológicas. Además de las altas temperaturas $\left(25^{\circ}\right.$ de promedio anual), densa vegetación y ondulantes colinas que caracterizan su posición entre las sierras y las tierras bajas tropicales, Jaén se extiende también en un punto transicional entre los húmedos Andes ecuatorianos al norte y los más áridos Andes peruanos al sur, una zona tradicionalmente usada para separar las áreas culturales de los Andes Septentrionales y Centrales (Guffroy 2008). La región también es distinta de otras áreas de la ceja de selva tales como Chachapoyas en donde las elevaciones son bastante bajas (1200-300 msnm) y el clima es más bien seco. A pesar de su proximidad a la cuenca amazónica, actualmente Jaén recibe pocas precipitaciones debido a la «sombra de lluvia». Generalmente las precipitaciones se limitan al periodo entre noviembre a marzo siendo el resto del año bastante seco, especialmente entre los meses de julio y agosto. Como resultado, la vegetación es xerotrópica, consistiendo de vegetación corta pero densa de matorrales espinosos y cactáceos.

Hacia al oeste de Jaén se ubica un tramo de los Andes donde la cadena se encuentra en su punto más bajo y estrecho (Raymond 1980). Aquí, múltiples sistemas ribereños con orígenes alto andinos (incluyendo el Chinchipe, Utcubamba, Huancabamba, y Chamaya) convergen en esta cuenca como tributarios del Marañón, los cuales en conjunción con los bajos pasos montañosos (p.e. El Paso de Paculla a $2140 \mathrm{msnm}$ ) forman corredores naturales que conectan la costa del Pacífico a la floresta amazónica, y los Andes Septentrionales y los Andes Centrales. En esencia, los pasos bajos e intersección de tributarios en la región de Jaén crean un nexo geográfico que podría haber conectado distintos medioambientes, ayudando a promover la interacción interregional entre la costa, la sierra y las tierras bajas tropicales en tiempos prehistóricos. 


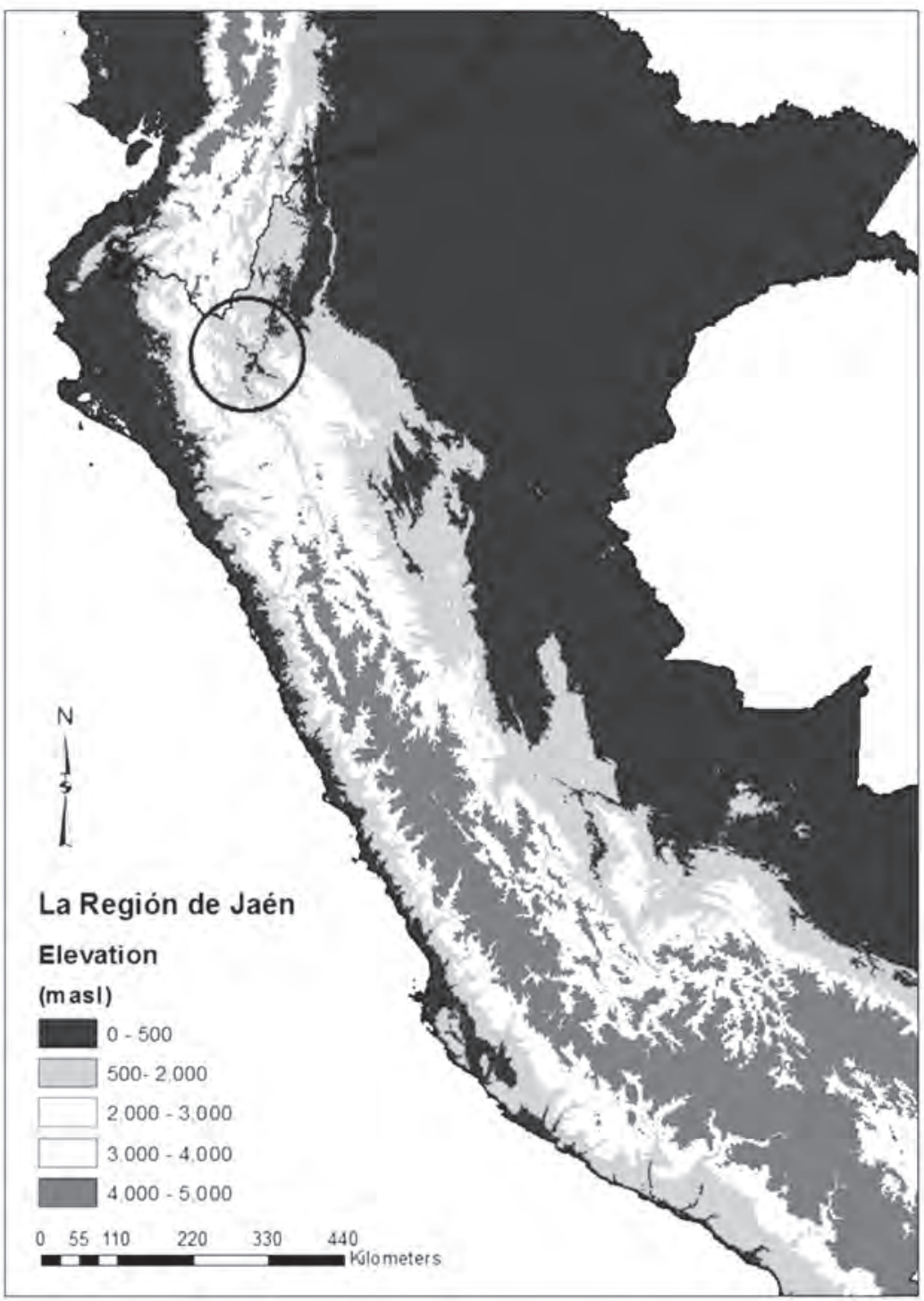

Figura 1. Ubicación de la región de Jaén.

La evidencia etnohistórica para la región soporta la idea de que Jaén fue un conducto de intercambio intercultural. Los Incas intentaron conquistar esta zona (Cieza León 1985 [1553]: 163; véase Niles 1999: 100-101; Taylor 1999: 201), posiblemente para controlar el intercambio de bienes exóticos que consideraban convenientes (entre estos podrían haber estado la coca, frutas tropicales, plumas de aves, alucinógenos, hierbas medicinales, mascotas y pieles de animales). Durante el periodo colonial temprano, las crónicas españolas documentaron intensivas redes de intercambio entre las poblaciones de la región de Jaén y grupos del sur de Ecuador, las tierras bajas tropicales y las sierras peruanas (Jiménez (ed.) 1897: 36-38; véase Shady 1987). La gente llegó a esta región a pie (posiblemente desde el oeste, norte y sur) y canoa (desde el este). De hecho, se notaron grandes canoas llevando 40-50 personas sugiriendo que el intercambio fluvial estuvo bien establecido. Algunos de los artículos producidos para el intercambio fueron la sal, el oro y objetos de piedra (Jiménez (Ed.) 1897: 36-38). 
Entonces, de acuerdo a las crónicas, la región de Jaén fue una ciudad central donde la población de diferentes zonas medioambientales concurrió a adquirir nuevos productos y los grupos locales fueron activos en la producción y el intercambio.

\section{HuAyurco y LA ARQUeOlogía de LA REgión DE JAÉN}

El potencial de la región de Jaén como un nexo para la interacción interregional se demostró arqueológicamente primero con el descubrimiento y excavación de Huayurco en 1961 por Pedro Rojas Ponce (1961, 1985) como parte de lo que fueron las investigaciones de la expedición original al Marañón de Julio C. Tello. El sitio de Huayurco está localizado cerca de la confluencia del Chichipe y Tabaconas a una altitud aproximada de 400-450 msnm (Fig. 2). Esta confluencia, junto con el ChinchipeMarañón aproximadamente $30 \mathrm{~km}$ aguas abajo, representa uno de los dos mayores puntos céntricos en la región de Jaén. Juntos, ellos conectan muchos de los mayores corredores del valle que conducen a la costa y sierra peruanas, las tierras bajas de la Amazonia y sur de Ecuador. Desde el punto de vista geográfico, Huayurco estuvo favorablemente situado para tener ventaja en las rutas de intercambio interregional que posiblemente podrían haber pasado por el sitio.

Las excavaciones de Rojas revelaron varias ofrendas que sugieren orígenes locales y foráneos (Lathrap 1970; Rojas 1985). Una simple botella de alfar marrón, una forma común en la parte tardía del periodo Inicial de los Andes centrales, aparecie-

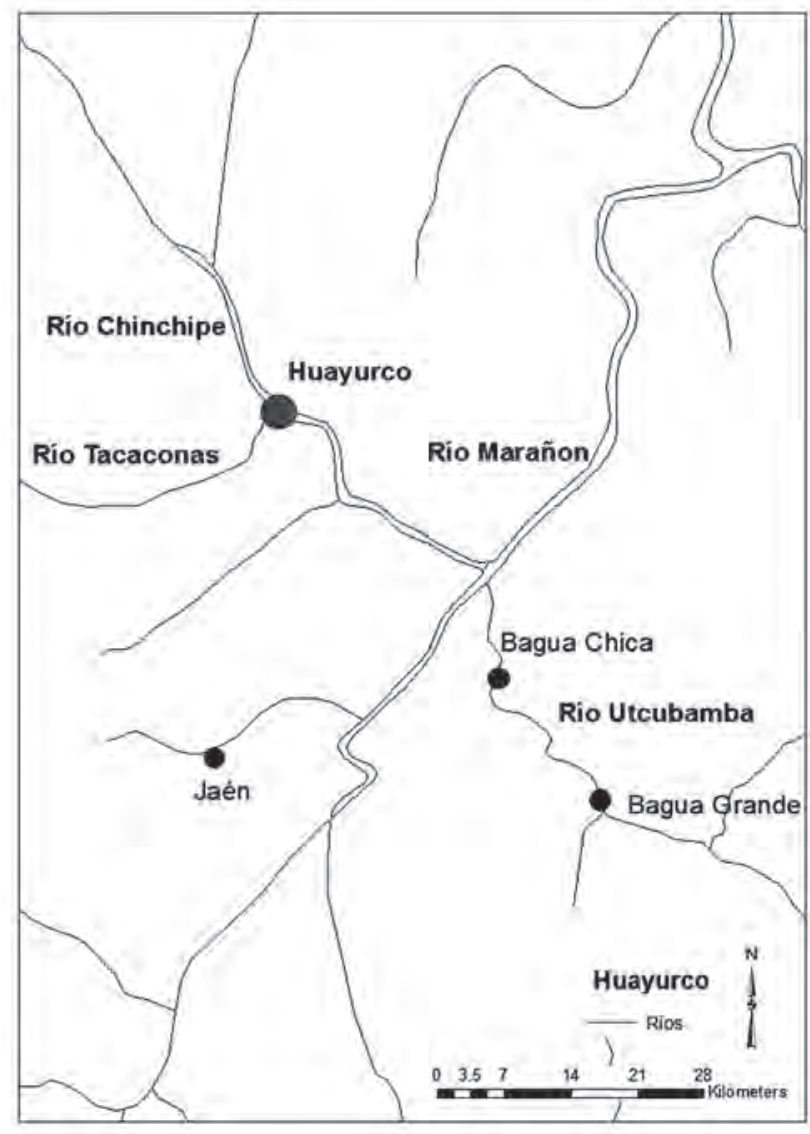

Figura 2. Mapa de Huayurco y los ríos principales. ron junto con productos de conchas marinas incluyendo grandes trompetas de conchas y cuentas en forma de peces. Además, Rojas encontró 12 cuencos de piedra finamente tallados y 130 fragmentos de cuencos de piedra. La finura de los cuencos varía entre finamente pulidos y ásperas superficies líticas de morteros. Algunos cuencos mostraron bordes ondulados y diseños incisos en su exterior.

La gran cantidad de estas vasijas fueron encontradas dentro de pequeñas unidades de excavación y la percepción que se tiene de algunos de los fragmentos es que fueron inacabados, todo esto llevó a Donald Lathrap (1970: 108) a sugerir que Huayurco fue un importante centro de producción para una tradición local de cuencos líticos. La presencia de cuencos de piedra similares encontrados en la costa y sierra del Perú (Lumbreras 2007: 285, Fig. 216, sp. 672a, b; Mohr-Chavez 1977: 718-719, Fig. 7.11, 7.12; Rojas 1961: 117 a-f), parece indicar que Huayurco fue activo en el intercambio a larga distancia. Esta idea fue reafirmada por la presencia de conchas marinas y el hecho que la iconografía de los fragmentos de la cerámica y los cuencos líticos compartieron rasgos estilísticos con tradiciones tempranas encontradas en sitios de la costa, sierra y tierras bajas tropicales (Lathrap 1970: 108). Estas 
observaciones condujeron a la idea de que Huayurco y la región de Jaén fueron muy involucradas en las tempranas redes de intercambio interregional conectando las sierras andinas con las tierras bajas de la floresta amazónica.

Sin embargo, a pesar del potencial que representaba Huayurco para conocer y explorar más estas tempranas redes de intercambio interregional en la ceja de selva, se realizaron muy pocas investigaciones en la región de Jaén en las siguientes décadas. Algunas excepciones a lo anterior señalado fueron los pequeños proyectos llevados a cabo por Jaime Miasta en los valles del Chinchipe y Tabaconas (Miasta 1979) y Ruth Shady y Hermilio Rosas sobre un área mayor en Bagua (1979; Shady 1973, 1987, 1999). El trabajo de Shady y Rosas fue de particular importancia en la creación de una secuencia cerámica general para Bagua y la región de Jaén durante el periodo Inicial y Horizonte Temprano, ayudando a demostrar los vínculos estilísticos compartidos entre sitios costeños, serranos y de la floresta tropical coetáneos.

En años recientes, Jaén ha visto un incremento en investigaciones arqueológicas. Estas incluyen investigaciones de Atsushi Yamamoto $(2007,2008)$ a lo largo del río Huancabamba; Quirino Olivera en la ciudad de Jaén, la confluencia del Chinchipe y el Marañón y Bagua (Atwood 2011; Olivera 1998; Sandoval 2012), Francisco Valdez (2008) en el valle Zamora-Chinchipe en el sur de Ecuador. Además, Daniel Morales (1992) completó excavaciones a lo largo del sistema del río Chambira un tributario del Marañón. Aunque este río se extiende mucho más al Este, cerca de la ciudad de Iquitos, permanece como una de las pocas áreas arqueológicamente investigadas a lo largo del bajo río Marañón. Estos proyectos están en varios estados de realización, sin embargo, cada uno aporta significativamente a un mejor entendimiento de la prehistoria de esta región.

\section{INVESTIGACIONES EN HuAYURCO}

Importante volver a mencionar que Huayurco está localizado en la confluencia de los ríos Chinchipe y Tabaconas, aproximadamente a 400-450 msnm. Aquí los valles están compuestos de onduladas colinas con graduales a abruptas inclinaciones sobre el piso del valle. Cerro Huayurco es muy prominente, y forma parte del borde derecho del valle Tabaconas con alturas de más de $450 \mathrm{~m}$ sobre el nivel del piso del valle. Muchas de las crestas hacen extensas repisas bajas y colinas que proporcionan áreas naturalmente planas sobre el piso del valle. Estos espacios, ahora y en el pasado, han sido usados por las poblaciones locales para actividades domésticas. El piso del valle varía en extensión cerca de la confluencia con el Tabaconas siendo considerablemente más ancho (casi un kilómetro) que el más profundamente encajonado río Chinchipe. Sin embargo, posiblemente cada uno podría haber proporcionado abundante tierra para la agricultura. Los ríos son torrentosos (mayor de $10 \mathrm{k} / \mathrm{h}$ ) debido a la inclinación de las sierras, sin embargo, generalmente ambos son estrechos y poco profundos. Durante la estación lluviosa, sin embargo, los ríos pueden expandirse y subir de nivel dramáticamente, ocasionalmente convirtiendo partes del piso del valle en pantanos de agua dulce.

Nuestro reconocimiento demostró que Huayurco, antes que un solo sitio monumental o montículo, actualmente es un complejo de al menos 12 concentraciones de arquitectura y materiales culturales alrededor de la confluencia (Fig. 3). Estos concentraciones cubren una extensión de 200 ha y varían mucho en cronología y función, han sido agrupados en primer lugar debido a su proximidad a la confluencia de los ríos y la distancia entre ellos es de menos 0,5 km. Sin embargo, se debe mencionar que la prospección ha sido informal y concentrada mayormente dentro de los tres kilómetros de la confluencia de los ríos -en todas direcciones- debido al tiempo y limitaciones logísticas. Podrían localizarse más concentraciones entre la densa vegetación xerotrópica a lo largo de los bordes del valle que hace difícil la visibilidad en el terreno. Sería necesario un reconocimiento de patrones de asentamiento formal con cateos de prueba extensivos para identificar y clarificar las relaciones temporales y funcionales entre los concentraciones. 


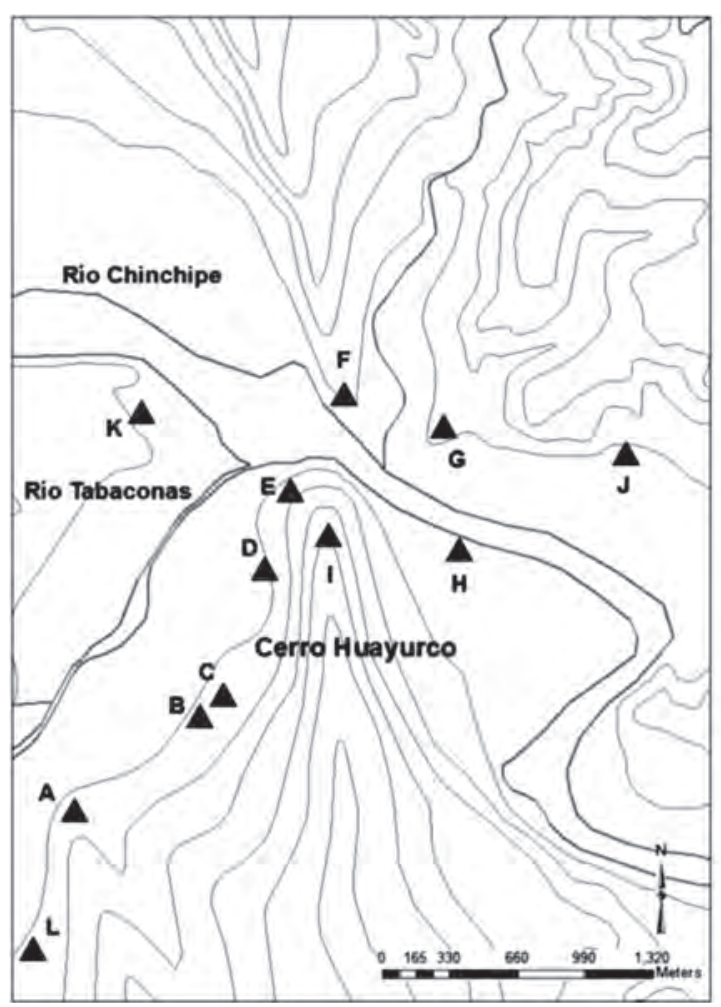

Figura 3. Mapa de los sectores de Huayurco.

Cada concentración estuvo bien posicionado sobre el nivel del piso del valle, tomando ventaja de las bajas repisas y colinas que se extienden a los largo de los bordes de los valles. Algunas de las colinas muestran evidencia de plataformas aterrazadas a través de la modificación de las inclinaciones naturales. Aunque es posible que concentraciones de arquitectura y materiales culturales a pequeña escala puedan haber estado localizados en el piso del valle, las crecidas estacionales y la naturaleza cambiante de los ríos posiblemente podrían haber (1) evitado asentamientos a largo plazo y (2) destruido algunos restos arqueológicos (véase Lathrap 1968). Un cateo de prueba ubicado sobre el piso del valle cerca al borde derecho del Tabaconas no reveló estratos ocupaciones y el nivel freático estuvo a menos de $1 \mathrm{~m}$ debajo de la superficie. Posiblemente, estas áreas fueron utilizadas para propósitos agrícolas incluyendo la producción de maíz, mandioca y palmas frutales, mientras que las actividades domésticas y rituales se ubicaron sobre las colinas y terrazas naturales a lo largo de los bordes de los valles. Una distribución de sitios similar ha sido identificada por Shady (1987, 1999; Shady y Rosas 1979) en Bagua y por Yamamoto (2008) a lo largo del Huancabamba.

La identificación de 12 concentraciones de arquitectura y materiales culturales alrededor de la confluencia complica significativamente nuestro entendimiento del tipo de sitio que existió en Huayurco. Entonces, antes que un sólo montículo o «huaca» correspondiente al Horizonte Temprano, hay múltiples concentraciones, muchos de los cuales (como ya se discutió) tuvieron diferencias temporales así como funcionales. La aparente preferencia por áreas planas sobre el nivel del piso del valle significa que algunas de las colinas y terrazas naturales también fueron reocupadas en diferentes ocasiones. El tamaño de Huayurco hizo más difícil el realizar una evaluación completa de la ocupación Horizonte Temprano del sitio descrito por Rojas (1985) y Lathrap (1970). Sin embargo, las múltiples ocupaciones con sus diferencias temporales permitió la oportunidad a hacer un estudio sobre la larga historia del sitio y la región en general.

Así, se condujeron excavaciones en múltiples concentraciones a fin de obtener un mejor entendimiento de sus relaciones temporales y espaciales. Las concentraciones fueron divididos en sectores (A-L) para el propósito de identificarlos bien. Desafortunadamente, el tamaño del complejo además del tiempo y restricciones financieras sólo permitió la excavación adecuada de unas pocas concentraciones. Por esta razón, las investigaciones primeramente se focalizaron sobre tres concentraciones: D y E localizadas sobre el borde derecho del Tabaconas, y G el cual estuvo ubicado sobre el borde norte del Chinchipe, adyacente a una pequeña quebrada. Antes que nada, cada componente (D, E y G), fue seleccionado por su fuerte evidencia de ocupación temprana, representada por la presencia de cerámica sobre la superficie. La cerámica era principalmente polícroma, incisa y con decoración incisa y polícroma, similar a los estilos del Horizonte Temprano encontrados en otras partes de la región de Jaén por Shady (1973, 1999; Shady y Rosas 1979) y Yamamoto (2008). 


\section{SECTOR D}

Las excavaciones se iniciaron en el Sector D, que está localizado a lo largo del banco derecho del río Tabaconas en la base del cerro Huayurco, aproximadamente $0,5 \mathrm{~km}$ al sur de la confluencia. Sobre la base de los registros de campo escritos por Rojas (1961), se sospechaba que sus excavaciones se habían realizado allí aunque esto no se podía asegurar. El Sector D es una baja colina natural, de aproximadamente 1 ha de área, separada del cerro Huayurco por un pequeño barranco hacia su borde este. Se han producido sustanciales modificaciones a la colina a través del aterrazamiento de las laderas naturales, creando dos plataformas separadas, una superior y otra inferior (Fig. 4). De las dos, la plataforma superior es significativamente más estrecha y larga. Mientras que los bordes orientales de las plataformas no son muy altos debido a la posición adyacente de la colina que es la falda ascendente del cerro Huayurco, el opuesto es notable y corre a lo largo del lado oeste. Aquí, la plataforma más baja se eleva más de $15 \mathrm{~m}$ sobre el piso del valle (la plataforma más alta se eleva más de $22 \mathrm{~m}$ ). Sin embargo, debemos reiterar, que estas elevaciones sólo fueron parcialmente alcanzadas a través de la construcción artificial.

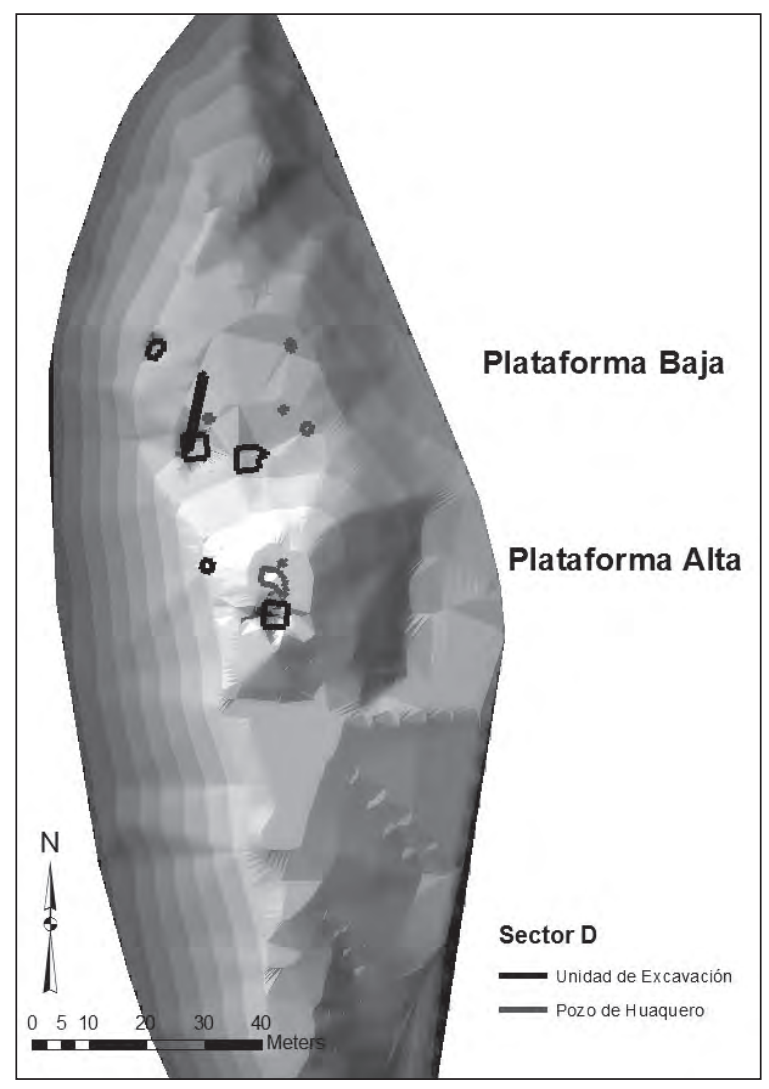

Figura 4. Mapa de Sector D.

Las excavaciones comenzaron sobre la plataforma superior donde se colocó una unidad de 4 x 4 $\mathrm{m}$ en el centro, cerca al borde norte de la terraza. Esta unidad exhibió aproximadamente $8 \mathrm{~m}$ de deposición cultural con, al menos, la presencia de dos fases mayores.

La fase superior representa una pequeña ocupación que data del Intermedio Temprano (100-600 d.C.). Las excavaciones revelaron una estructura rectangular toscamente construida hecha de piedras locales y cantos rodados (Fig. 5).

La función de la estructura parece haber sido en su mayor parte doméstica ya que en su interior se encontró gran cantidad de fragmentos de vasijas para cocina y huesos de animales. Los huesos de animales pertenecían principalmente a grandes mamíferos incluyendo camélidos y venado de cola blanca (Vásquez y Rosales 2012). También se encontraron dos fogones revestidos de piedra en los lados opuestos de la unidad. Cada uno de los fogones contenía huesos de animales y fragmentos de cerámica. Aunque se usaron principalmente piedras de campo no modificadas para recubrir fogones, para este propósito, los habitantes locales también reciclaron viejos instrumentos de piedra (tales como morteros de piedra).

La cerámica asociada con esta ocupación fue una mezcla de vasijas domésticas de cocina y una combinación de cántaros con cuello largo, cuencos y vasijas de doble pico y asa puente. El modelado y las aplicaciones fueron rasgos comunes, incluyendo cántaros de cara gollete representando humanos y algunas veces animales. Los ojos de las vasijas fueron de forma redondeada o granos de café. Muchas de las vasijas también fueron decoradas en pintura fugitiva post cocción blanca, negra y roja. La técni- 


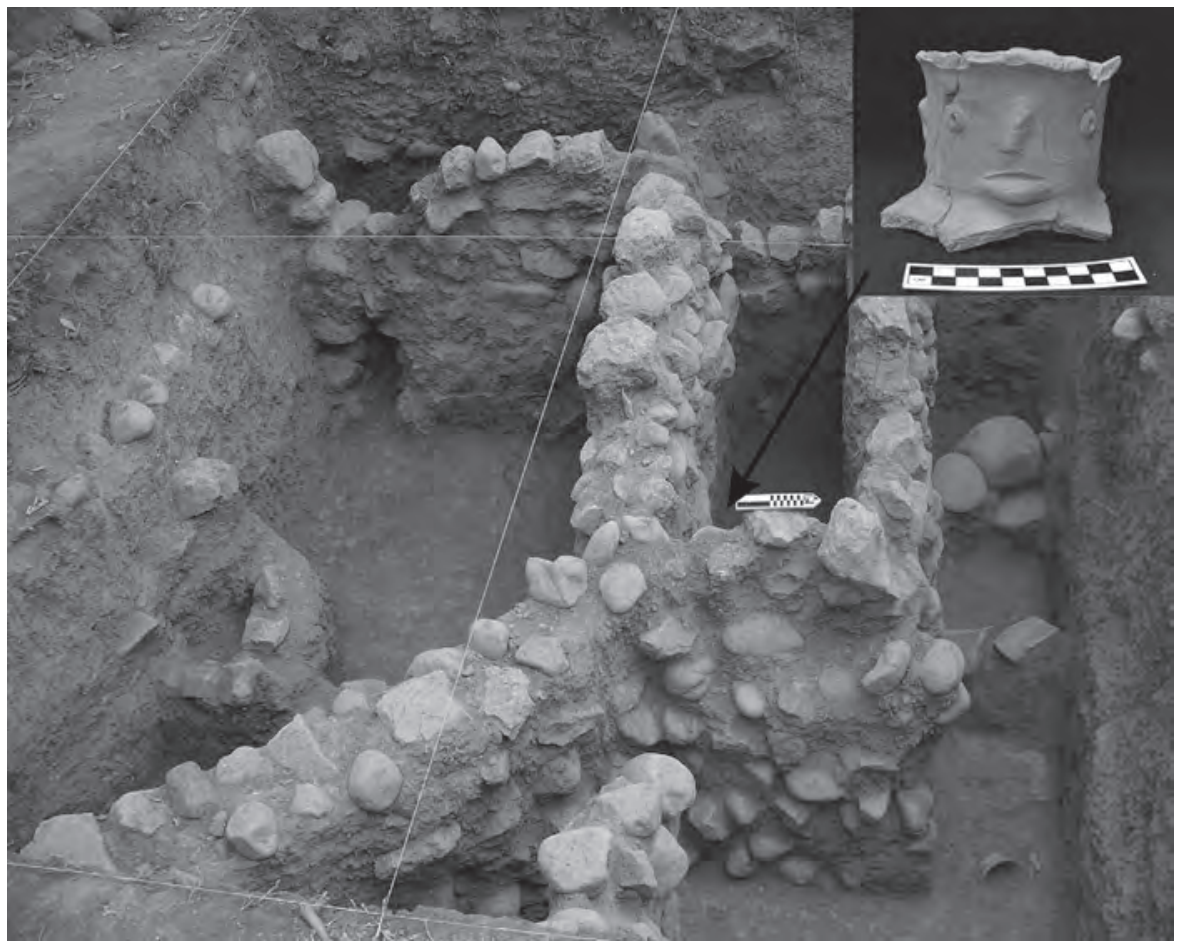

Figura 5. Sector D: Estructura con ubicación de ofrenda de cántaro cara gollete (fotos: Ryan Clasby).

ca del pintado se usó principalmente en los cuerpos destacando algunos rasgos anatómicos o atuendos sobre vasijas de forma antropomorfa. No obstante, también se usó para delinear diseños geométricos simples. Dos fechados radiocarbónicos ponen esta fase por el periodo Intermedio Temprano (cal. 2 sigma: 394-539 d.C; 256-417 d.C. '; véase Fig. 16). La cerámica tiene algunas semejanzas estilísticas a los estilos Panzaleo y Puruha del centro de Ecuador (por ejemplo, véase Bray 1995; Jijón y Caamaño 1997: 215-217, Figs. 233-246; Valdez 2008: 875, Fig. 43.4).

Las excavaciones de esta estructura doméstica también revelaron la presencia de ofrendas de cerámica. Un cántaro cara gollete había sido colocado debajo de una de los muros (Fig. 5). La vasija fue colocada con la cara hacia arriba y la mitad frontal del cuerpo había sido removida antes de haber sido depositada. Desafortunadamente, no se encontraron restos macrobotánicos ni de fauna en el interior pero la colocación de la vasija debajo de la esquina de uno de los muros sugiere que puede estar relacionada a una conmemoración ritual relacionada a la construcción del edificio. Es posible que esta ofrenda tenga relación al acto de colocar restos de animales o entierros humanos (acompañados de otros artefactos debajo de la esquina de los cimientos de edificaciones, una tradición andina común que se extendió hasta el siglo XX (Burger 1992: 74). Las ofrendas se destinaron a asegurar el éxito de las actividades que se llevaron a cabo en el sitio.

Al norte de la unidad se ubicó un pozo de huaqueo aproximadamente al mismo nivel de la ocupación del Intermedio Temprano. El perfilado y limpieza del pozo de huaqueo reveló la presencia de dos botellas de doble pico y asa puente gemelos de forma de animales, uno macho y otra hembra de acuerdo a los rasgos que mostraban los genitales (Fig. 6a). Aunque no tenían las cabezas, la forma de los animales parece ser de jaguares o un felino silvestre más pequeño, como una oncilla u ocelote

1 Todos de los fechado radiocarbónicoss son basados por la curva de calibracíon de OxCal ShCal 04, 2 sigma. 
debido a la presencia de marcas moteadas negras sobre la piel sobre un fondo blanco en la botella del macho. Esta botella fue de interés particular pues la cola se curvaba hacia arriba alrededor del pico posterior y así también tenía grabado pintura con marcas alineadas en forma de diamantes negros (Fig. 6b). Esto sugiere que fue una representación de la cola transformándose en una serpiente.
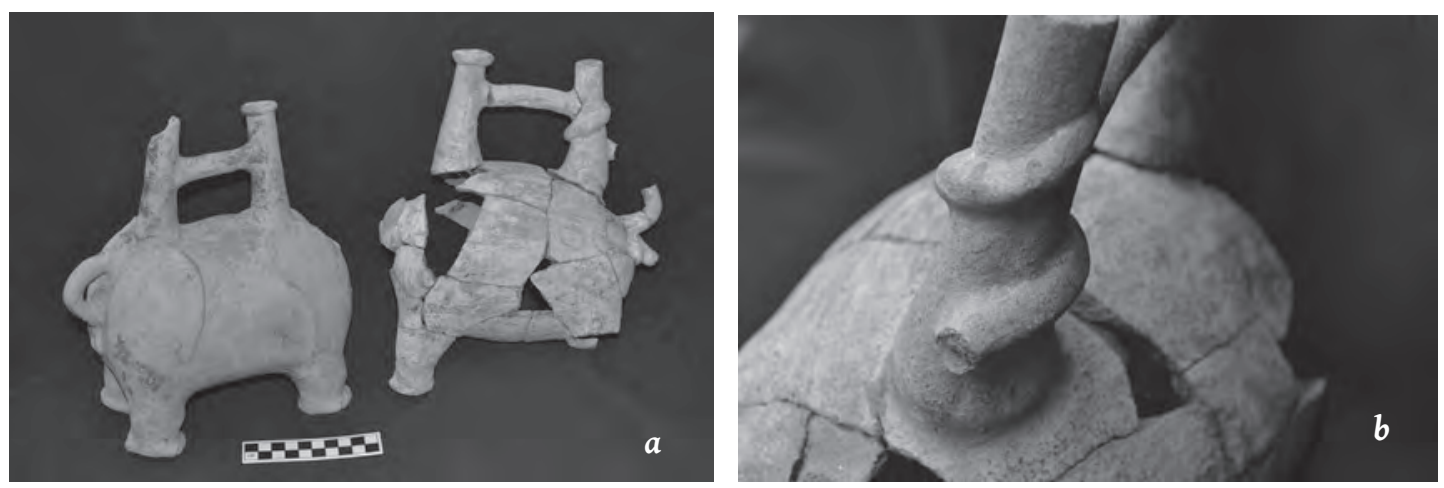

Figura 6. Sector D: a. dos botellas de doble pico y asa puente gemelos de forma de felinos. b. La cola contenía grabado pintura con marcas alineadas en forma de diamantes negros. (Fotos: Ryan Clasby).

La representación de esta transformación y dualismo parece surgir de elementos específicos de la cosmología amazónica, particularmente en relación al chamanismo y el uso de sustancias psicotrópicas (véase Burger 1992; Elera 1993; Reichel-Dolmatoff 1975; Roe 1982; Stone 2011). Ambos animales (serpiente y felino) representan elementos centrales en las transformaciones shamánicas y aparecen tambiém frecuentemente en el arte precolombiano representando las prácticas chamánicas (Burger 1992; Larco 1941; Stone 2011).

Las excavaciones en la unidad revelaron una ocupación temprana a aproximadamente 6 a $8 \mathrm{~m}$ de profundidad. Esta ocupación fue definida por un muro de unos $2 \mathrm{~m}$ de altura que apareció corriendo de este a oeste a través de la plataforma (Fig. 7a). Adyacente al muro y a lo largo de su base se ubicaron dos pisos, cada uno mostrando pequeños fogones no revestidos. No se pudo determinar la función del muro ya que sólo se podía excavar en un reducido espacio debido a la profundidad. Sin embargo, estuvo solo y localizado cerca al borde norte de la plataforma. La altura del muro sugiere que las actividades que ocurrían en su interior no podían ser vistas desde la plataforma inferior. Sin embargo, en ese lugar pudo haber un punto de acceso desde la plataforma inferior, como puede ser en el borde este del muro comenzando desde el extremo aproximadamente a la mitad de la plataforma. Así, futuras excavaciones en el centro de la terraza podrían revelar una calzada o escalera conduciendo desde la plataforma inferior a la superior. La cerámica de esta fase fue pequeña pero se identificaron formas de cántaros y botellas. Los bordes de los cántaros fueron engrosados o reforzados hacia el exterior con una fina línea ondulada incisa ubicada directamente debajo de éstos (Fig. 7b). En algunos casos, se encontró pintura blanca post cocción cubriendo la incisión debajo del borde. Dos fechados radiocarbónicos colocan a esta fase en la parte temprana del primer milenio d.C. (cal. 2 sigma: 86-251 d.C; 231-403 d.C.; vease Fig. 16).

Asimismo, se abrió una unidad de 4 x $4 \mathrm{~m}$ en la plataforma baja. Esta unidad estaba cerca a lo largo del borde oeste de la plataforma y se podía visualizar un muro desde la superficie. La excavación reveló que el muro tenía aproximadamente $2 \mathrm{~m}$ de alto por su interior (Fig. 8). El muro fue construido con piedra local y cantos rodados, pero al igual que la mampostería en la plataforma superior, no se halló evidencia clara de uso de mortero en su construcción. Ésta sección de muro sufrió un elevado índice de erosión, presentándose una gran acumulación de derrumbe por su lado interior (Este) y, debido a el patrón colapso, se cree que pudo haber estado repellado originalmente. Inmediatamente al éste del 

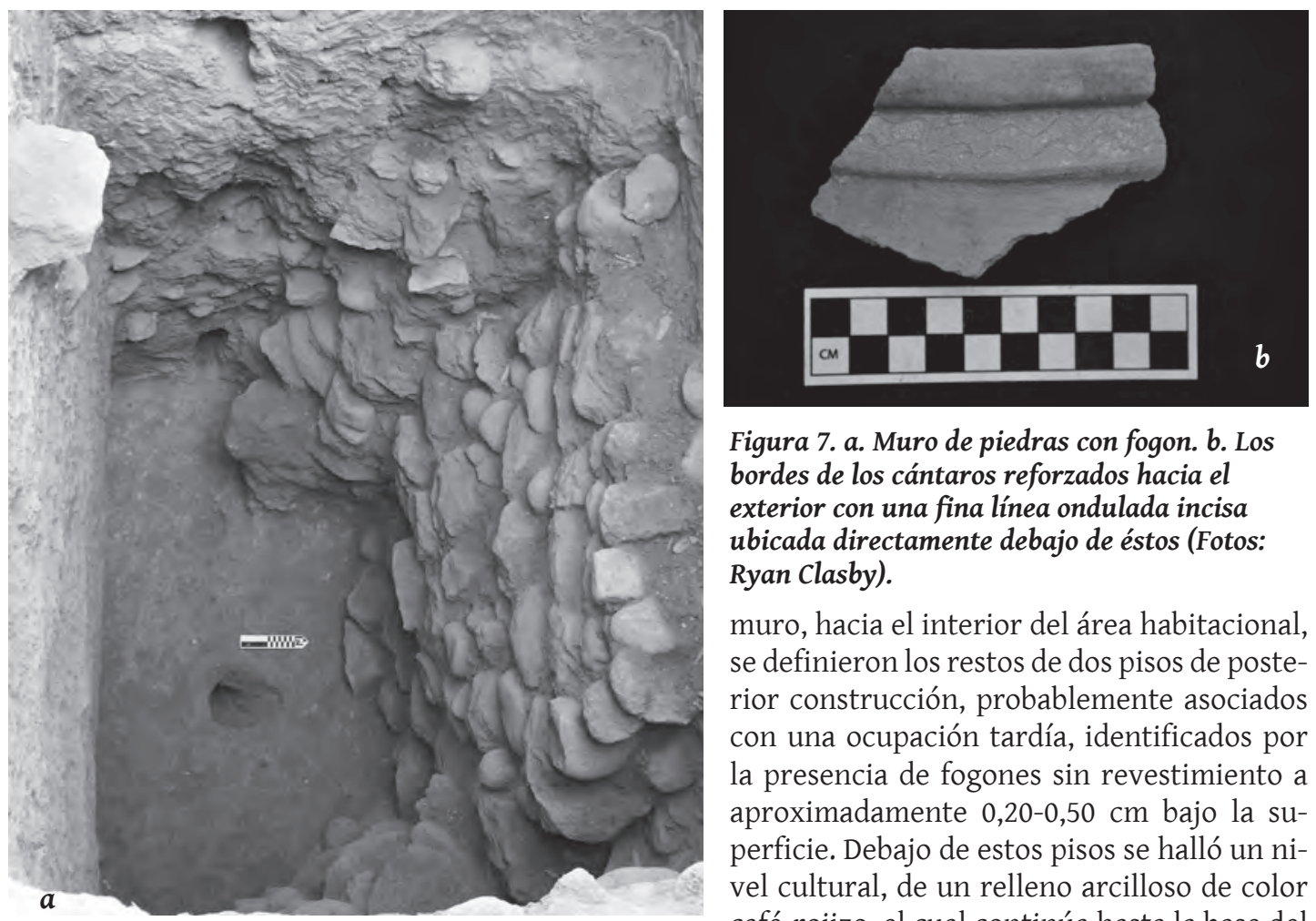

Figura 7. a. Muro de piedras con fogon. b. Los bordes de los cántaros reforzados hacia el exterior con una fina línea ondulada incisa ubicada directamente debajo de éstos (Fotos: Ryan Clasby).

muro, hacia el interior del área habitacional, se definieron los restos de dos pisos de posterior construcción, probablemente asociados con una ocupación tardía, identificados por la presencia de fogones sin revestimiento a aproximadamente $0,20-0,50 \mathrm{~cm}$ bajo la superficie. Debajo de estos pisos se halló un nivel cultural, de un relleno arcilloso de color café-rojizo, el cual continúa hasta la base del muro, a unos $(2,5 \mathrm{~m})$ de profundidad.

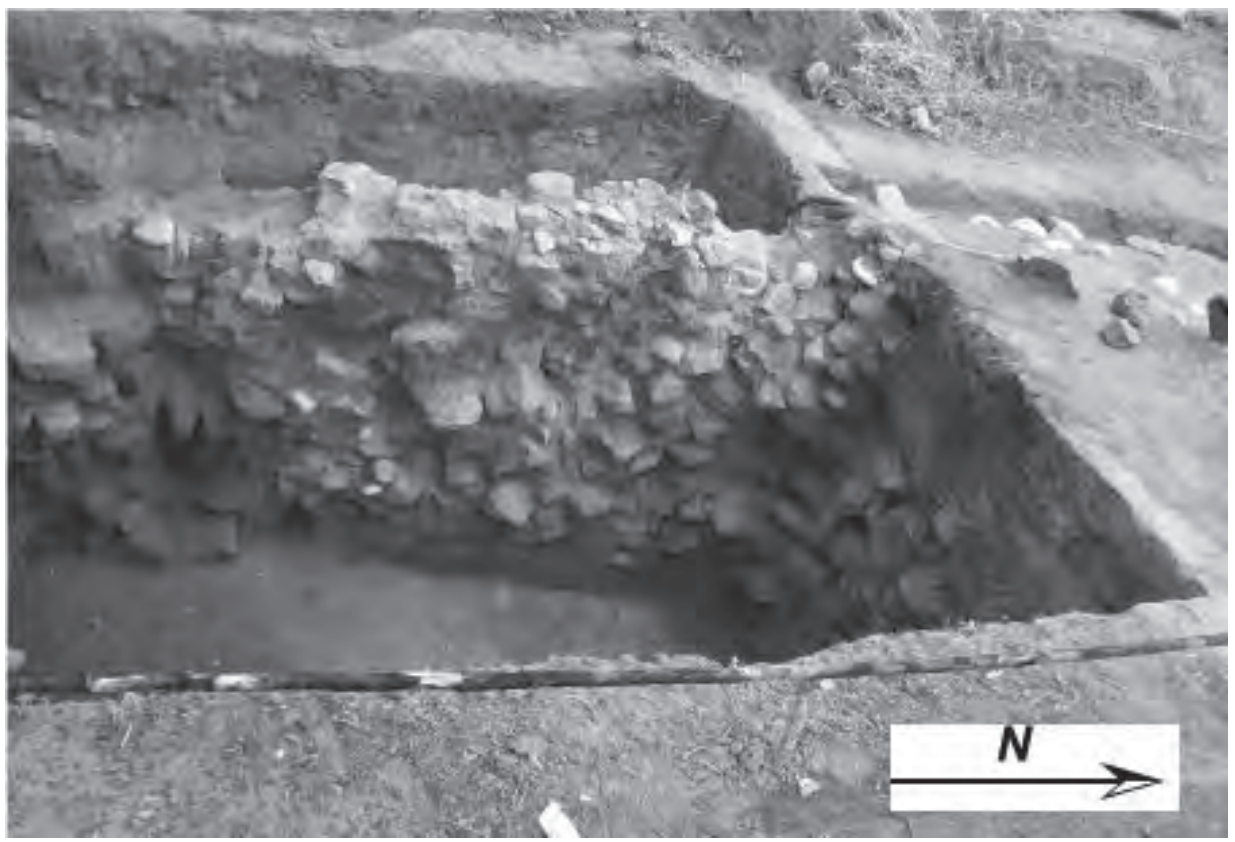

Figura 8. Lado interior (Este) del muro por la plataforma baja (Foto: Ryan Clasby). 
Desafortunadamente, hubo una significativa mezcla de material cerámico en este nivel debido a la erosión del muro así como del piso asociado con este, evitando el fechamiento claro de este muro. Sin embargo, se sospecha que ésta pared es contemporánea con el gran muro encontrado en la base de la unidad de $8 \mathrm{~m}$ de profundidad sobre la plataforma superior. La construcción de ambos muros es muy similar tanto en la técnica como los materiales utilizados, y algunos fragmentos de cerámica asociados con el muro presentan bordes reforzados con incisiones onduladas al igual que los encontrados en la plataforma superior dentro de un contexto que aparenta pertenecer a una fase más temprana.

Los grandes muros pertenecientes a la ocupación del primer milenio habrían requerido una sustancial cantidad de labor y parece improbable que hayan sido erigidos sólo para propósitos domésticos. Es más posible que su función estuviera relacionada a alguna actividad comunal o pública (posiblemente ceremonial o defensiva). En la medida que la evidencia es limitada para corroborar alguna de estas hipótesis, debe tenerse en cuenta que la cantidad de área expuesta por nuestras investigaciones fue muy pequeña debido a la profundidad del estrato cultural. Es interesante mencionar que no se encontró un muro paralelo sobre el borde este de la plataforma inferior. Esto puede ser debido al hecho que el terraplén no es empinado y que cerro Huayurco se extiende directamente adyacente, es así que hubiera innecesario construirlo.

\section{SECTOR G}

El Sector G está localizado sobre el borde norte del río Chinchipe, directamente adyacente a la pequeña quebrada y tiene una extensión aproximada de 3 ha. Aunque muestra evidencias de modificación humana el Sector $G$ representa el fin de una pequeña cadena de colinas con 3 plataformas naturales. Se encontró cerámica del Horizonte Temprano sobre la superficie pero sólo la plataforma media tuvo evidencia de estratigrafía intacta. La falta de estratigrafía intacta sobre las plataformas superior e inferior puede ser debido a la erosión pero también es posible que las ocupaciones principales, ocurridas durante el Horizonte Temprano, estuvieran localizadas sobre la plataforma media. Esta plataforma es más grande y considerablemente más plana que las otras dos, sugiriendo que las ocupaciones se organizaron en esta área. Este hecho fue confirmado a través de nuestras excavaciones, las cuales mostraron que los habitantes originales pusieron unos $15 \mathrm{~cm}$ de una capa de roca roja molida estéril en ciertas partes de la plataforma media a fin de crear una terraza plana para un eventual sitio de construcción. Posiblemente esta roca molida fue extraída de las colinas cercanas.

La estratigrafía de la plataforma media del Sector $G$ fue relativamente superficial, menos de $1 \mathrm{~m}$ de profundidad en el centro y sólo $2,5 \mathrm{~m}$ a lo largo del borde, permitiendo una exposición horizontal más extensa del sitio, abarcando un área de aproximadamente 20 x $20 \mathrm{~m}$. Aquí, las excavaciones revelaron una estructura rectangular con múltiples cuartos (Fig. 9, 10). Los muros de la estructura fueron cortos y hechos de cantos rodados, usualmente

Figura 9. Sector G y la ubicación de las excavaciones.

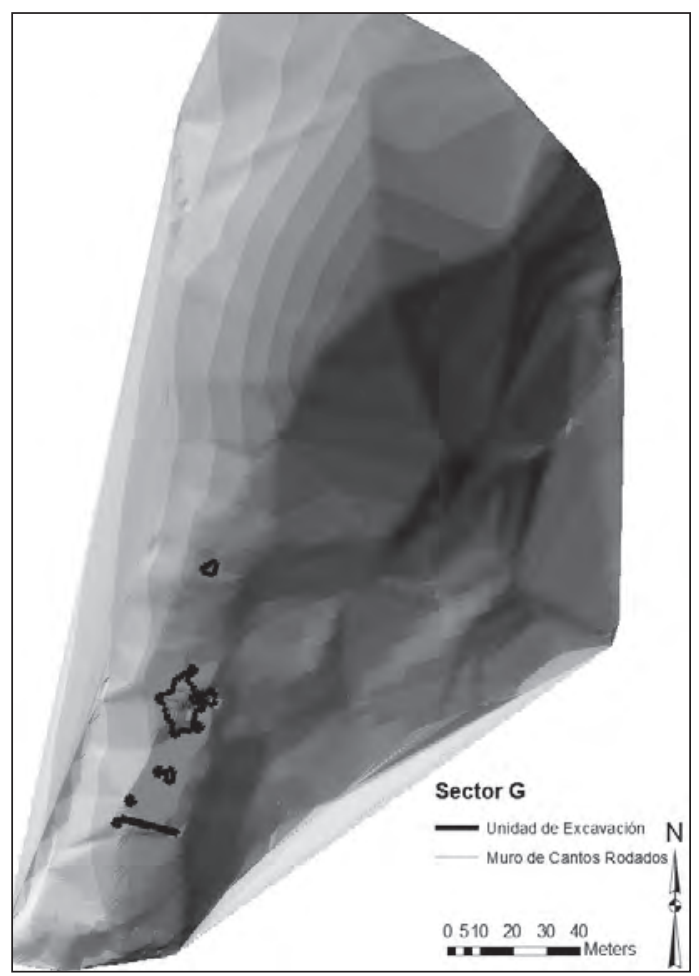




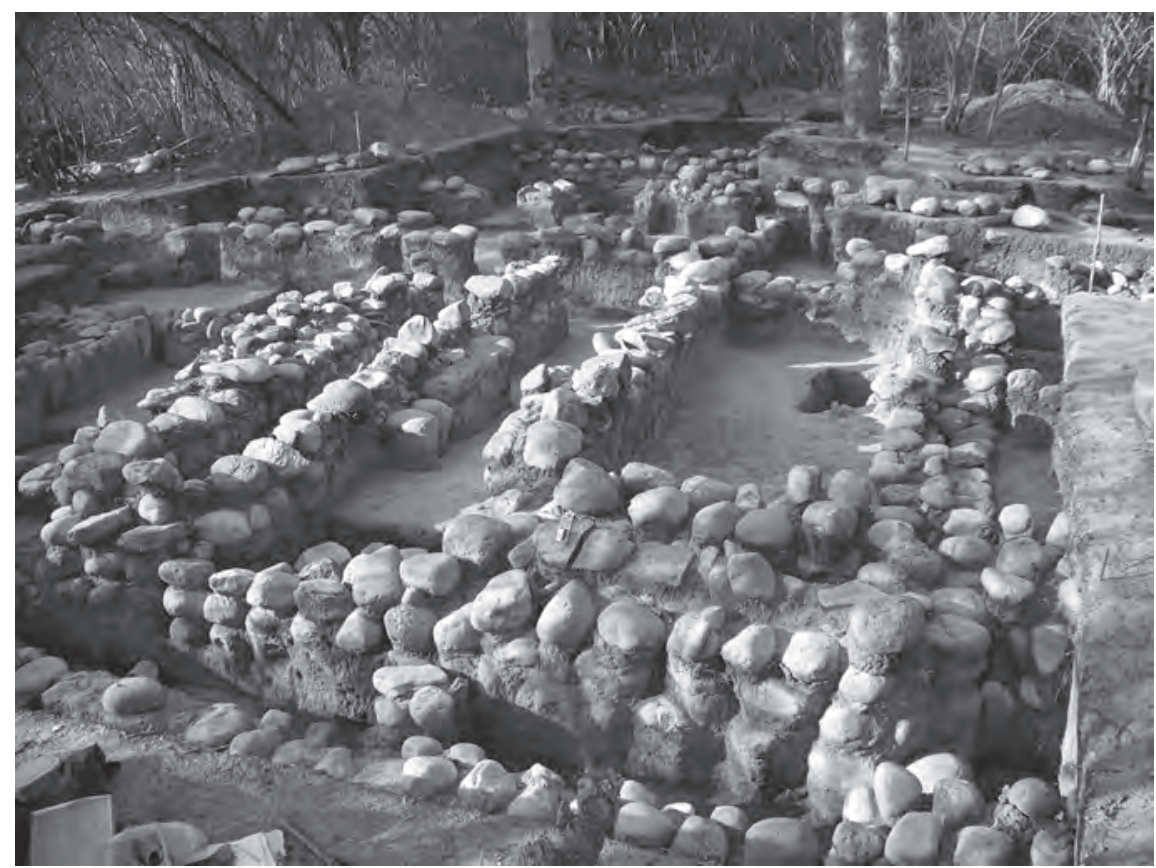

Figura 10. Estructura rectangular en Sector G (Foto: Ryan Clasby).

de no más de 2 o 3 hileras de alto y unidas con una suave argamasa amarilla. Los cantos rodados podrían haber sido recolectados localmente de la quebrada adyacente o de los bancos del río Chinchipe. Ya que los muros fueron relativamente bajos, podrían haber sido cimientos que luego fueron cubiertos con paja, madera o alguna otra superestructura perecible.

Se identificaron tres cuartos rectangulares en el lado sur del complejo. Cada cuarto fue de aproximadamente $2 \mathrm{~m}$ de ancho por $6 \mathrm{~m}$ de largo (Fig. 11). Al norte de estos cuartos se ubicaron una serie de muros perpendiculares que corrían a través del ancho de la plataforma, separados uno del otro por aproximadamente $3 \mathrm{~m}$. La arquitectura estuvo asociada con al menos dos pisos, aunque el piso más inferior sólo se evidenció en la mitad sur de la unidad. El piso mismo fue difícil de distinguir ya que su exposición las lluvias y el crecimiento de la vegetación daño su integridad. Sin embargo, los fogones y una acumulación más grande de carbón ayudaron a identificarlo.

En tanto que la función de la estructura no está clara parece, sin embargo, haber sido de naturaleza ceremonial. La cerámica encontrada en los depósitos sobre el piso consiste casi exclusivamente en tiestos de cuencos y cántaros decorados. Se identificaron pocos fragmentos diagnósticos llanos. Frecuentemente, los cántaros fueron carenados y con cuello corto mientras que los cuencos tendieron a ser de forma globular. Las técnicas decorativas más frecuentes fueron: incisión, pintado, incisión zonal polícroma y punteado.

Los colores más comunes fueron el rojo, negro y blanco, dichos colores frecuentemente fueron aplicados con las técnicas de pre y post cocción. La forma más ubicua de decoración fue la doble hélice incisa o volutas que se disponen horizontalmente alrededor de la vasija (Fig. 12a, b). Este diseño se da sobre cuencos (frecuentemente en pintura blanca post cocción enmarcado por engobe rojo) y sobre cántaros carenados (también con pintura blanca post cocción).

Cada cuarto en la estructura mostró evidencia de múltiples fogones sin revestimiento (Fig. 13). En algunos casos, se podía encontrar cinco o seis en un área de $2 \times 2 \mathrm{~m}$, frecuentemente sobrepuestos. Usualmente, estos fogones fueron poco profundos, no más de 20 a $30 \mathrm{~cm}$ de profundidad y estuvieron 


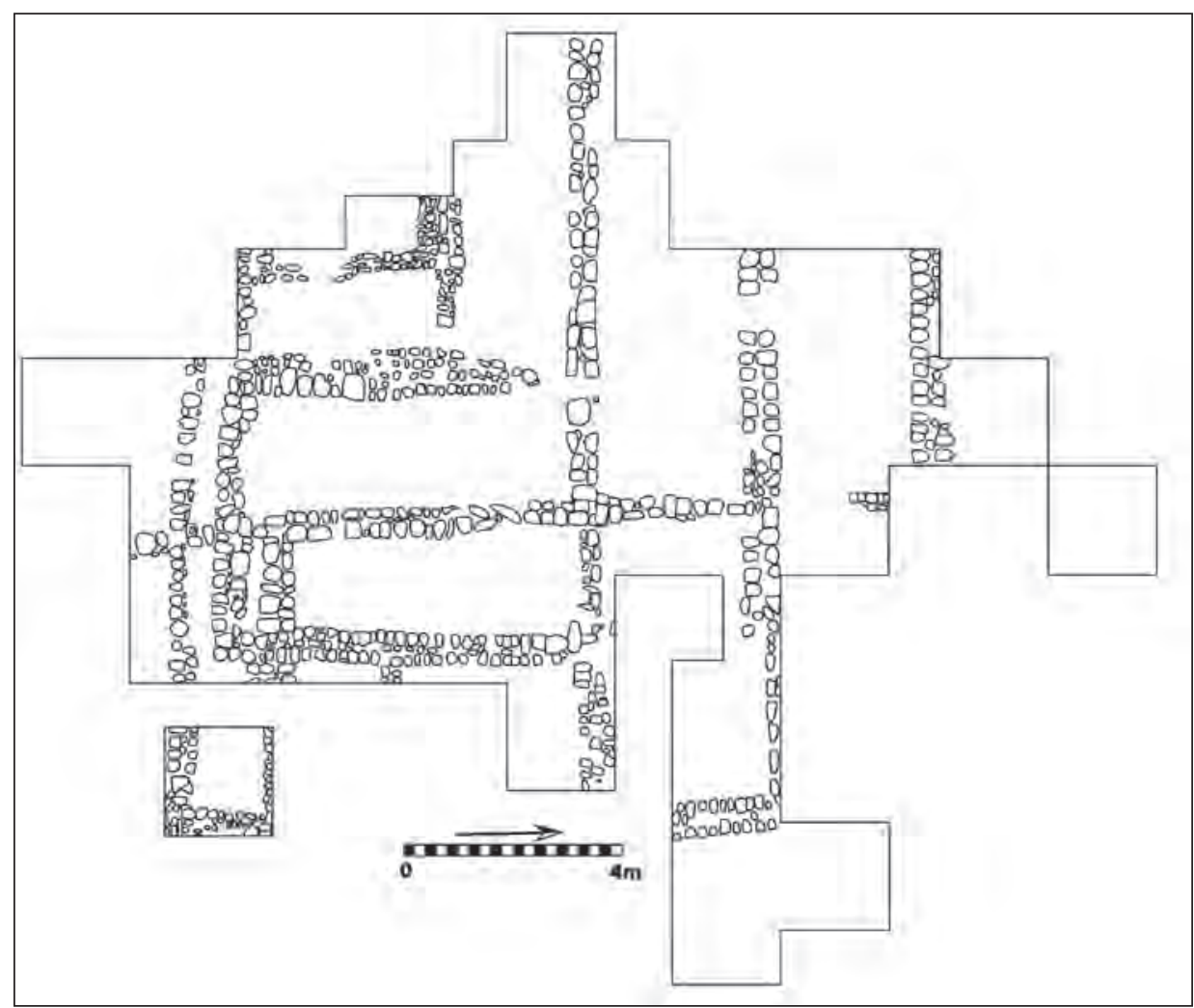

Figura 11. Plano de la estructura rectangular en Sector G, emarcado por las unidades de excavación.
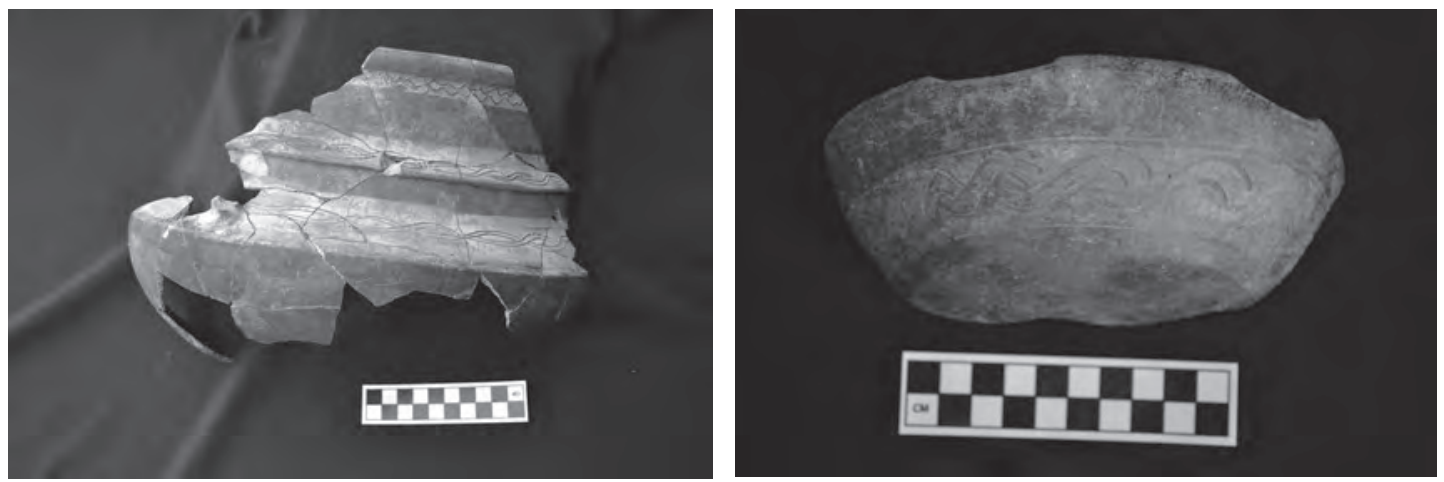

Figura 12. a. Ejemplo de vasija con decoración de la doble hélice incisa que se disponen horizontalmente alrededor de la vasija. B. (Fotos: Ryan Clasby).

enmarcados por gruesas líneas quemadas de color naranja. La ceniza dentro del hoyo, usualmente, fue muy oscura.

Parece que los ocupantes mayormente quemaron materiales orgánicos, como lo muestran restos apenas visibles en el contenido de los fogones. No obstante, se encontraron unos pocos fragmentos de cerámica además de huesos de animales (mayormente peces locales de río y crustáceos) (Vásquez y Rosales 2012). Sin embargo, algunos fogones también contenían huesos quemados de felino (Vásquez y Rosales 2012), probablemente asociados con especies de la floresta más pequeñas o medianas tales 


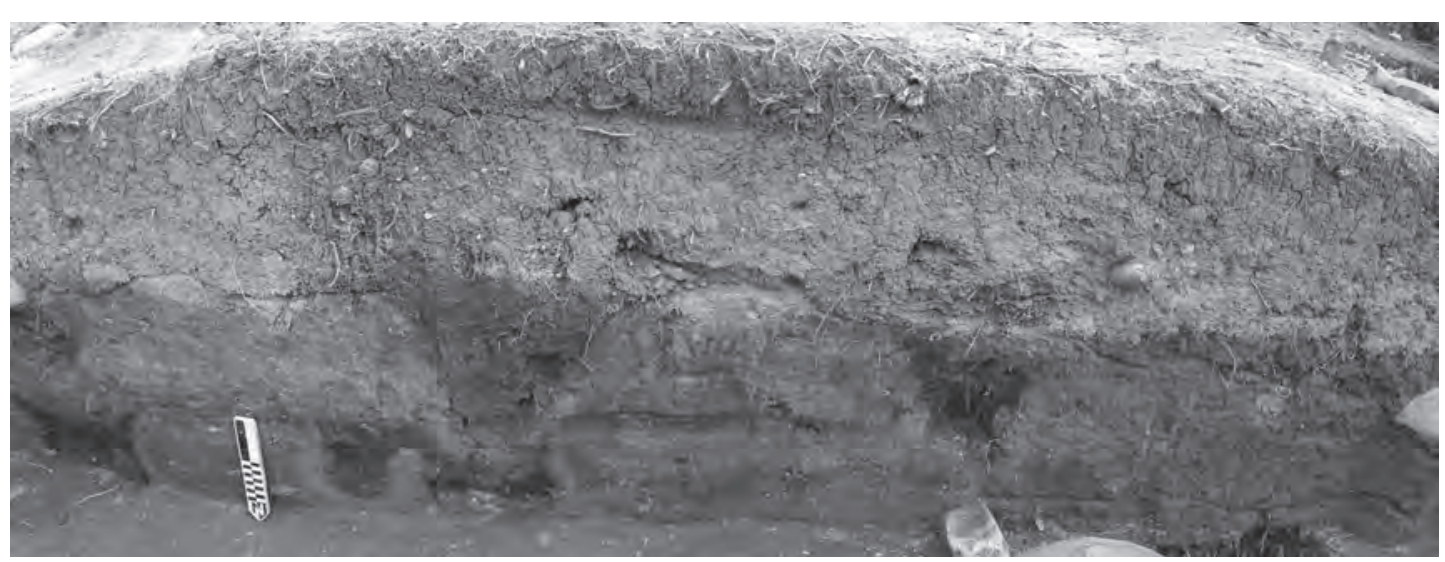

Figura 13. Fogones sin revestimientos (Foto: Ryan Clasby).

como el tigrillo. De acuerdo con Víctor Vásquez y Teresa Rosales, ninguno de los huesos mostraban marcas de cortes lo cual puede indicar que felinos pequeños o medianos fueron llevados al sitio, posiblemente para tenerlos como mascotas, rituales u objeto de intercambio. Se necesitará de mayor investigación para esclarecer este tema.

Los restos de animales encontrados sobre el piso fueron una mezcla de especies incluyendo productos rivereños locales, es así que se encontraron restos de venados, cuyes, armadillos y lagartijas (Vásquez y Rosales 2012). También productos marinos (p.e. peces, crustáceos y ostra perlera), junto con animales de la floresta tropical como la paca y capibara en muy pequeñas cantidades.

La evidencia para el uso ritual de la estructura también se basa en la presencia de varias ofrendas encontradas en el interior de la edificación. Además de los depósitos esparcidos de cerámica, también se encontraron collares de cuentas de piedra y concha marina. El collar de conchas (Fig.14) fue de particular importancia pues fue una clara indicación de las relaciones a larga distancia de Huayurco. Nuestras excavaciones mostraron que este no fue un hallazgo aislado pues se descubrieron, en el interior de la edificación, numerosos fragmentos de concha marina trabajada. Los análisis de Gladys Paz (2011) identificaron tres tipos de especies marinas (Pinctada mazatlanica, Strombus gracilior, Prunum curtum) importadas de aguas más cálidas de la costa del extremo norte del Perú y sur de Ecuador.

El significado ritual del Sector $G$ también es evidente por su patrón funerario único. J. Marla Toyne (2012) hizo el análisis de los restos humanos. Se recuperaron al menos 26 individuos en la plataforma media, futuras excavaciones revelarán probablemente más.

Dos de los entierros fueron colocados en el medio de la plataforma antes de su construcción incluyendo un adulto que fue parcialmente enterrado debajo de uno de los muros. Justo al sur y debajo del piso principal fue un individuo asociado a los restos de un camélido y un fragmento de un mortero lítico.

23 individuos fueron encontrados a lo largo del borde este de la plataforma

Figura 14. Collar de concha del mar (Foto: Ryan Clasby).

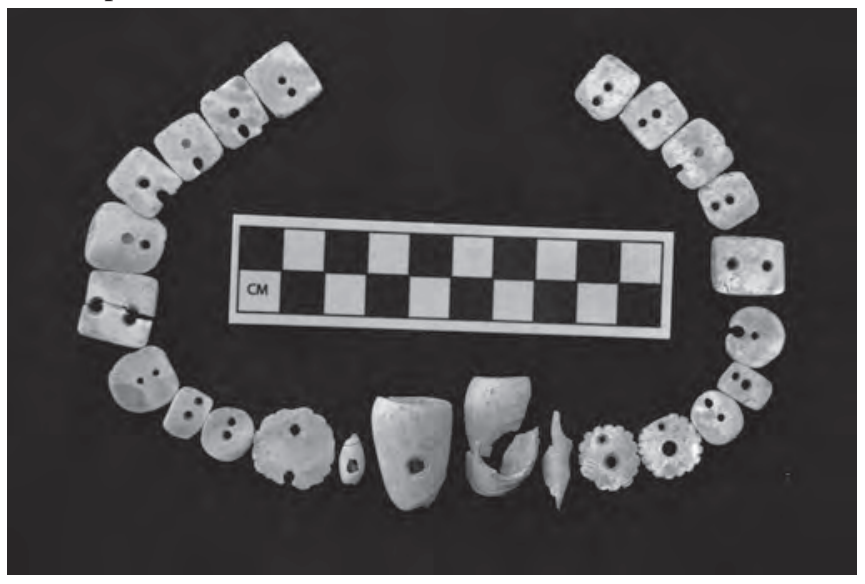


debajo del muro externo original de la estructura. Aunque algunos de los individuos parecen corresponder a entierros primarios, la mayoría de los esqueletos fueron encontrados incompletos (algunas veces sólo consistían de cráneos) y mezclados, lo cual podría sugerir que algunos contextos corresponded a depósitos secundarios. Sin embargo, no se debe de descartar la irregular preservacion de los esqueletos para explicar esto (Toyne 2012). De hecho la mayoría de estos individuos provienen de unos espacios de 6 × 2 m y 2 × 2 m. Sólo un entierro estuvo acompañado de ofrendas, en este caso un hacha de piedra y una pequeña pulsera o collar hecho de cuentas de piedra azul (similar al lapislázuli) y concha.

Quizás de modo muy significativo, 19 de los individuos encontrados en la estructura corresponden a individuos menores a los 11 años (9 infantes, 10 niños) (Toyne 2012). Únicamente fueron identificados 7 adultos, aunque estos frecuentemente mezclados con jóvenes. Si estos resultados no están sesgados, una posibilidad debido tanto al diseño del muestreo así como la pobre preservación de los restos, es posible sugerir que hubo una tendencia hacia entierros de jóvenes en las áreas excavadas. Como se creía usualmente que los huesos de los niños e infantes se deterioran más rápido que los de los adultos, estos resultados permitirían contradecir la mayoría de suposiciones sobre edad y preservación sostenidas actualmente (Toyne 2012; véase Bello et al. 2006).

Siete fechados radiocarbónicos dataron la estructura del Sector $G$ en el Horizonte Temprano. Estas muestras fueron tomadas de fogones en el piso en el centro de la estructura, mientras otras dos se tomaron de estratos al lado del complejo cerca el muro exterior. Cuatro de los fechados cayeron aproximadamente entre 750- 400 a.C. (cal. 2 sigma) mientras que tres de las fechadas tuvieron un rango de 400-2 a.C (cal. 2 sigma; véase Fig.16). Es posible que esta ocupación sea dividida en dos fases dentro del Horizonte Temprano. Se espera la compleción del análisis de la cerámica y los resultados de fechados radiocarbónicos adicionales.

\section{Sector E}

Este sitio fue localizado sobre el área aplanada de una cresta al norte del Sector D por el mismo lado del rio Tabaconas, a menos de 0,3 km de la confluencia. Cubre una pequeña área, menos de $50 \mathrm{~m}$ de ancho entre las empinadas laderas del cerro Huayurco al este y el piso bajo del valle al oeste. Podría haber sido un área potencialmente peligrosa para los asentamientos previos ya que, ocasionalmente, hubieran podido rodar grandes rocas desde lo alto del cerro Huayurco, usualmente durante los periodos de actividad sísmica. Actualmente, se emplazan sobre partes del sitio al menos dos rocas. No fue visible arquitectura sobre la superficie pero los pozos de huaqueo y la erosión de las laderas de la cresta han expuesto cerámica de las capas culturales inferiores.

En esta área, se ubicaron seis unidades de $2 \times 2 \mathrm{~m}$, cada una conteniendo 2,5 a $3 \mathrm{~m}$ de estratos culturales debajo de la superficie. Las excavaciones en esta zona revelaron tres fases. La última de las fases fue similar, en términos de estilo cerámico, a la posible ocupación del Horizonte Medio encontrada en la plataforma superior del Sector D. Se identificaron múltiples fogones sin revestir pero ninguna arquitectura asociada con esta ocupación. Una segunda fase fue descubierta directamente debajo. Sin embargo, no estuvo asociada con ninguna arquitectura. Esta fase no será discutida aquí pero posiblemente data de la segunda mitad del primer milenio D.C.

La fase más temprana fue encontrada en aproximadamente 2,5 a $3 \mathrm{~m}$ debajo de la superficie y data del Horizonte Temprano (732-390 a.C; 516-262 a.C.: cal. 2 sigma; véase Fig. 16). La arquitectura relacionada a esta fase fue escasa pero se identificó una corta cimentación hecha de cantos rodados así como también la presencia de dos fogones revestidos. Uno de los fogones tuvo piedras colapsadas en el medio cubriendo restos de ceniza oscura (Fig. 15). De algún modo, este fogón es similar al fogón horno llamado «Pachamanca» usado en la sierra andina. Los huesos de animales correspondientes a esta ocupación consistió principalmente de pequeñas lagartijas, ranas y especies rivereñas tales 


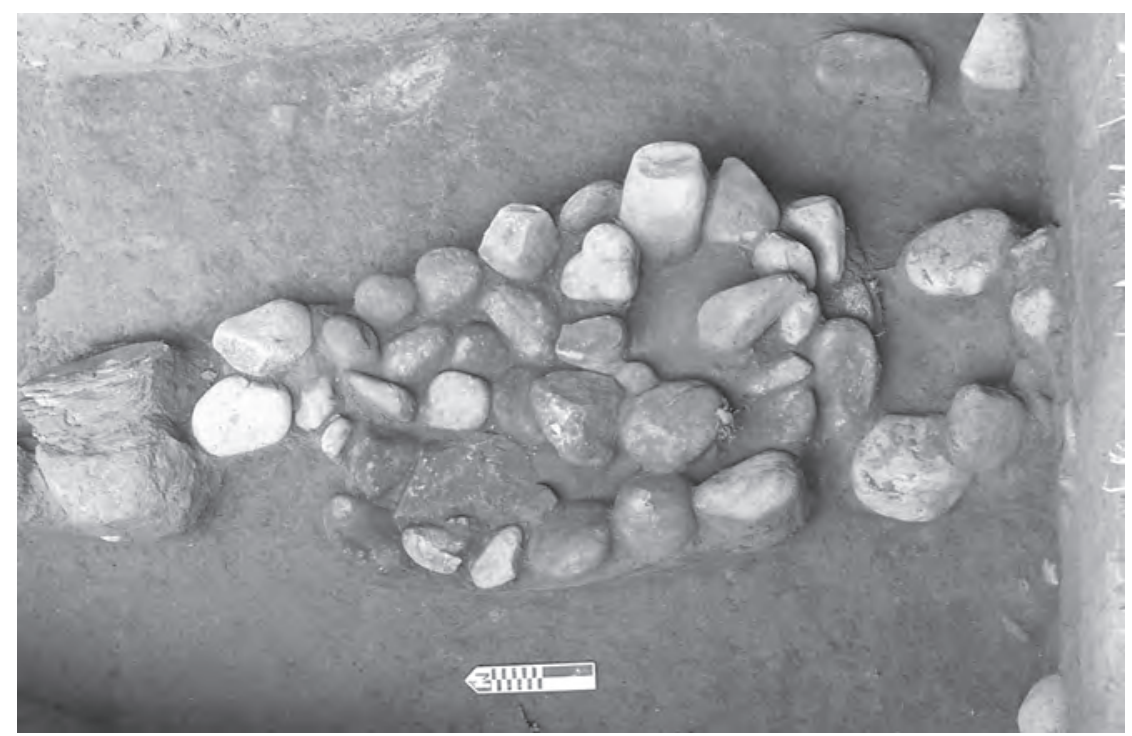

Figura 15. Fogón con piedras colapsadas en el medio cubriendo restos de ceniza oscura (Foto: Ryan Clasby).

como peces y crustáceos (Vásquez y Rosales 2012). También se encontraron pequeñas cantidades de conchas de especies marinas (Pinctada mazatlanica; Strombus gracilior; Prunum curtum), revelando las mismas especie de aguas cálidas identificadas en el Sector G (Paz 2011). Una vez más, posiblemente el propósito principal fue como materia prima para elaborar pequeños bienes suntuarios tales como cuentas y pendientes.

La cerámica de este nivel fue típica del Horizonte Temprano, caracterizada por los tipos de negro pulido fino, incisión polícroma, y punteado en zonas (véase Burger 1992; Shady 1987, 1999). La mayor parte de las vasijas recuperadas fueron de cántaros de cuello corto y cuencos aunque una porción significativa de la cerámica también parece ser tosco alfar doméstico. La carencia de arquitectura significativa para esta fase puede sugerir que mayormente fue una pequeña ocupación doméstica. Aparentemente similar a la cerámica recuperada del Sector $G$, parece ser una fase distinta, de este modo, es necesaria mayor precisión cronológica.

\section{DiscUSIÓN}

Los resultados de nuestra prospección y excavaciones muestran que no sólo fue un sitio considerablemente más grande de lo que fue originalmente reportado, con un complejo de múltiples concentraciones esparcidas sobre 200 ha, sino que ciertos sectores han sido más o menos continuamente ocupados desde los comienzos del primer milenio a.C. hasta, al menos, el final del primer milenio d.C. Es probable que Huayurco fue también ocupado más tarde en la prehistoria de los Andes. En adición de las ocupaciones descubiertas, muchos de los sectores muestran evidencia de cerámica corrugada por la superficie, un tipo de estilo de cerámica que fue común por muchas partes de la ceja de selva (Guffroy 2006). Jean Guffroy (2006) aduce que las variaciones de este estilo en el sureste de Ecuador y noreste de Peru están asociados con la difusión de las lenguas de los grupos Jibaros después 1000 d.C.

La complejidad de Huayurco se visualiza mejor en el Sector G. Como mencioné, hay una tendencia hacia entierros de jóvenes, esto podría tener un significado a modo de ritual relacionado a la construcción de la estructura, un acto que es paralelamente frecuentemente en los Andes centrales donde se enterraban niños bajo los cimientos de las estructuras para asegurar su éxito (Burger 1992:74). 


\begin{tabular}{|c|c|c|c|c|}
\hline Lab №. & Sector & Contexto & ${ }^{14}$ C. B.P. & $2 \sigma(\mathrm{ShCal} \mathrm{04)}$ \\
\hline Beta:320431 & D & $\begin{array}{l}\text { Plataforma alta, de la fase más } \\
\text { temprana, encontrado en un fogón } \\
\text { asociado con el muro. }\end{array}$ & $1790 \pm 30$ & A.D. $231-403$ \\
\hline D-AMS:1175 & D & $\begin{array}{l}\text { Plataforma alta, de la fase más } \\
\text { temprana, encontrado en un fogón } \\
\text { asociado con el muro. }\end{array}$ & $1888 \pm 26$ & A.D. $86-251$ \\
\hline D-AMS:1178 & $\mathrm{D}$ & $\begin{array}{l}\text { Plataforma alta, de la fase más } \\
\text { reciente, encontrado en un fogón } \\
\text { asociado con la estructura. }\end{array}$ & $1751 \pm 26$ & A.D. $256-417$ \\
\hline D-AMS:1177 & $\mathrm{D}$ & $\begin{array}{l}\text { Plataforma alta, fase más reciente, de } \\
\text { un fogón asociado con la estructura. }\end{array}$ & $1663 \pm 25$ & A.D. 394-539 \\
\hline Beta:320433 & G & $\begin{array}{l}\text { De un fogón asociado con la estruc- } \\
\text { tura. }\end{array}$ & $2440 \pm 30$ & 732-390 B.C. \\
\hline Beta:320434 & G & $\begin{array}{l}\text { De un fogón asociado con la estruc- } \\
\text { tura. }\end{array}$ & $2270 \pm 30$ & 386-196 B.C. \\
\hline Beta:320436 & G & $\begin{array}{l}\text { Cerca un muro exterior de la estruc- } \\
\text { tura, asociado con entierros. }\end{array}$ & $2470 \pm 30$ & 750-398 B.C. \\
\hline D-AMS:1179 & G & $\begin{array}{l}\text { De un fogón asociado con la estruc- } \\
\text { tura. }\end{array}$ & $2148 \pm 29$ & 203-2 B.C. \\
\hline D-AMS:1180 & G & $\begin{array}{l}\text { De un fogón asociado con la estruc- } \\
\text { tura. }\end{array}$ & $2422 \pm 31$ & 727-382 B.C. \\
\hline D-AMS:1183 & G & $\begin{array}{l}\text { De un fogón asociado con la estruc- } \\
\text { tura. }\end{array}$ & $2219 \pm 32$ & 362-96 B.C. \\
\hline D-AMS:1184 & G & $\begin{array}{l}\text { Cerca el muro exterior de la estruc- } \\
\text { tura. }\end{array}$ & $2413 \pm 28$ & 718-376 B.C. \\
\hline Beta:320432 & E & $\begin{array}{l}\text { De un fogón asociado con la } \\
\text { fase más temprana. }\end{array}$ & $2440 \pm 30$ & 732-390 B.C. \\
\hline D-AMS:1217-405 & E & $\begin{array}{l}\text { De un fogón asociado con la } \\
\text { fase más temprana. }\end{array}$ & $2394 \pm 25$ & 516-262 B.C. \\
\hline
\end{tabular}

Figura 16. Cuadro de fechas radiocarbónicas (AMS).

Los múltiples entierros de jóvenes individuos debajo de los muros además de ofrendas exóticas, cerámica fina y un despliegue de pequeños fogones sobrepuestos sugieren que esta estructura tuvo alguna clase de significado ritual. El número y distribución de los fogones sugiere la posibilidad de breves pero frecuentes ceremonias centradas en rituales de quema. La presencia de huesos quemados de felinos salvajes en lentes de fogones sostiene esta idea. Mientras la naturaleza de esta hipótesis está siendo todavía evaluada, la arquitectura y la distribución horizontal de sus rasgos y artefactos sugiere de un patrón de la ceja de selva única el cual puede no haber tenido antecedentes directos ni en la sierra si en las tropicales tierras bajas. De hecho, muros o cimientos de piedras similares y paredes que constan de grandes bloques han sido descubiertos por Olivera (Atwood 2011) en Montegrande cerca de la ciudad de Jaén y Valdez (2008) en Santa Ana-La Florida a lo largo del Zamora-Chinchipe al sureste de Ecuador. Ambos sitios parecen datar de periodos mucho más tempranos que Huayurco y pueden representar antecedentes de las tradiciones arquitectónicas del Sector $\mathrm{G}$.

La iconografía cerámica de Huayurco durante el Horizonte Temprano es particularmente interesante. Stone (2011: 41) sostiene que la espiral de doble hélice se refiere a la «caapi vine/snake/spiral 
configuration»(liana caapi/serpiente/ configuración de espiral), y ésta es una mezcla de símbolos inherentes a la transformación chamánica a través del uso de sustancias psicotrópicas. Aunque, aparentemente, vinculado a símbolos de la selva, las variaciones de doble hélice se encuentran en varios sitios en la costa, sierra y la ceja de selva del norte del Perú durante el periodo Inicial Tardío y el Horizonte Temprano. Esto incluye el Jequetepeque medio y bajo (Elera 1998; Sakai y Martínez 2008: 180, Fig. 3F; Tsurumi 2008: 153, Fig. 13); Cajamarca (Terada y Onuki 1982: lamina 86); Kuntur Wasi (Inokuchi 2008: 227, Fig. 2b); Pacopampa (Morales 2005: 227, Fig. 18); el rio Huancabamba (Yamamoto 2008: Fig.20); y Bagua (Shady 1999: 205, Fig. 2d.). La naturaleza ubicua de este diseño indica, posiblemente, una tradición compartida entre la costa, la sierra y los grupos de las tierras bajas durante el periodo Inicial Tardío y el Horizonte Temprano (Nesbitt 2012: capítulo 13). De hecho, hubo una expansión de las redes de intercambio durante este periodo con una mayor variedad en los tipos de productos que se movían (Burger 1992). Esto se da conjuntamente con el incremento en el uso compartido de símbolos iconográficos. Quizá la doble hélice fue de los muchos símbolos familiares, incluyendo el jaguar y la serpiente que señalan una conexión mayor entre distintas poblaciones basadas en chamanismo y el uso de sustancias psicotrópicas. En efecto, estos símbolos pueden haber contribuido a unir varias culturas a través de una ideología compartida, la cual pudo haber tenido implicancias prácticas relacionadas al intercambio y la interacción.

Estas redes de intercambio son evidentes con la presencia de los restos de malacológico y animales en Sector G. Como menciono, la variedad de los restos de animales en la colección muestra clara evidencia de especies de la costa, sierra y la floresta tropical, además de las locales (incluyendo peces, crustáceos, lagartijas, venado y armadillo). Debe señalarse que algunas especies son consideradas como «exóticas» al área tales como la paca, el capibara y felinos silvestres, no obstante en tiempos prehistóricos esta podría haber sido su geografía natural. Dado que la naturaleza de este intercambio no es clara, la presencia de la chaquira y collares de especies malacológicos sugieren que las personas de Huayurco deseaban o valoraban estos objetos exóticos para su uso en actividades no-domesticas.

Por el pequeño tamaño de las especies arriba mencionadas, Paz (2001) propone que fueron traídas especialmente a la región como materias primas para la producción de bienes santuarios tales como cuentas y pendientes.

El sitio de Huayurco continúo a ser ocupado durante el periodo Intermedio Temprano experimentando cambios dramáticos con respeto a la organización del sitio. Los habitantes hicieron terrazas en el Sector D y construyeron muros grandes por cada plataforma, esto podría haber tenido funciones ceremoniales o de defensa. Por 500-600 años (100-600 d.C.), este sector fue el centro de muchas reconstrucciones, es así que se construyeran más de $6 \mathrm{~m}$ de deposición cultural culminando en una estructura con funciones domésticas. La naturaleza de las relaciones interregionales de Huayurco cambiaron también. A pesar de que las excavaciones continuaron demostrando evidencia de restos de malacológicos y animales exóticos, estos disminuyeron en importancia. La cerámica de este periodo también llega a ser menos variada y a mostrar conexiones más fuertes con las culturas de la sierra sur y centro de Ecuador en vez de la costa de Perú sugiriendo que Huayurco cambio el enfoque de sus relaciones interregionales económicas.

Algunas tradiciones se mantuvieron, sin embargo las ofrendas del periodo Intermedio temprano como la de los dos felinos gemelos sugieren que la transformación chamánica y las imágenes de la selva todavía estaban importantes para la ideología local. Como menciono, la botella encontrada en el pozo de huaquero del Sector D, tiene forma de un felino masculino y fue manchado como un jaguar así también tiene una cola que se transforma en una serpiente. Stone (2011: 40-42) sostiene que frecuentemente las serpientes invocan el simbolismo de las lianas del ayahuasca el cual contiene propiedades alucinógenas y que las serpientes representan una fase liminal durante el proceso de alucinación (véase Stahl 1986; Stone 2011) conduciendo la transición desde formas geométricas a seres espirituales más complejos como el jaguar. La colocación de estas vasijas en un contexto de ofrenda 
y sin cabezas puede ser una expresión de un ritual que involucraría una transformación shamánica, revelando el tipo de prácticas espirituales en las cuales estuvo comprometida esta comunidad.

Con respecto a la idea que Huayurco fue un centro de producción de cuencos de piedra, queda por determinarse. Fuera del fragmento de mortero ya discutido y una superficie encontrada con finos diseños tallados, no se recuperaron cuencos de piedra durante el curso de nuestras excavaciones. Hasta que más de estas vasijas sean encontradas en contexto, es difícil evaluar su significado y función en las culturas locales. De los recientes trabajos en la región, sólo Valdez (2008) ha encontrado estas vasijas en contexto (como parte de una ofrenda). Sin embargo, al menos 100 de estas vasijas de piedra están presentes en museos locales en Jaén y Bagua sugiriendo que fueron ampliamente producidos en la región, posiblemente en un largo periodo de tiempo.

En cualquier caso, los resultados de las excavaciones iniciales indican que Huayurco y la región de Jaén han tenido una larga y compleja historia que estamos sólo comenzando a entender. La próxima cronología ayudaría a definir cada una de las ocupaciones temporalmente así como también darnos luces del desarrollo de las comunidades de las ceja de selva en la región de Jaén.

Los resultados de las excavaciones en Huayurco acentúan la necesidad de investigaciones adicionales en la región de Jaén y la ceja de selva. Y también ha proporcionado soporte adicional a la idea que la ceja de selva estuvo bien vinculada con la sierra de los Andes, la costa y las tierras bajas de la Amazonia; como sociedades no pertenecientes a entidades culturales aisladas sino que más bien participando dentro de mosaicos o redes sociales interregionales (Kohl 2008; véase Lesser 1985; Nesbitt 2012: capitulo. 13; Pauketat 2001, 2007; Wolf 1982). Mayores investigaciones son necesarias para entender mejor los desarrollos culturales en la ceja de selva si deseamos apreciar cabalmente los procesos culturales que se dieron entre los Andes y las tierras bajas tropicales, y viceversa. Las investigaciones continuas en la ceja de selva ayudaran a dilucidar los procesos que condujeron al desarrollo cultural de las tres regiones.

\section{Agradecimientos}

La investigación en Huayurco fue realizada gracias al apoyo de MacMillan Center, Josef Albers Travelling Fellowship, y NSF Doctoral Dissertation Improvement Grant. BCS-0951661. Agradecemos de forma particular a Victor Falcón Huayta por la traducción de inglés a español y a Richard Burger, Lucy Salazar, Helaine Silverman y Jason Nesbitt por todas sus sugerencias. También a Víctor Vásquez, Teresa Rosales, Gladys Paz, y J. Marla Toyne por su colaboración en el proyecto, y a mis amigos de Huayurco y Jaén por su interés en el desarrollo de esta investigación. 


\section{BibLIOGRAFÍA}

ALCONINI, Susan

2004 «The southeastern Inka frontier against the Chiriguanos: structure and dynamics of the Inka imperial borderlands». Latin American Antiquity 15: 389-418.

ATWOOD, Roger

2011 «Top 10 Discoveries of 2010: Early Pyramids-Jaén, Peru», Archaeology, 64(1), enero/febrero. Disponible en <http://www.archaeology.org/1101/topten/peru.html>. [Acceso el 11 de octubre de 2012].

BELLO, S., A. THOMANN, M. SIGNOLI, O. DUTOUR y P. ANDREWS

2006 «Age and sex bias in the reconstruction of past population structures». American Journal of Physical Anthropology 129: 24-38 .

BUSH, M., J. HANSELMAN y H. HOOGHIEMSTRA

2011 «Andean montane forests and climate change». En: Tropical Rainforest Responses to Climatic Change, 17 (2): 33-54

BURGER, Richard

1984 «Archaeological areas and prehistoric frontiers: the case of Formative Peru and Ecuador». En: D.L. Browman, R.L. Burger y M.A. Rivera (eds.) Social and Economic Organization in the Pre-Hispanic Andes, pp. 33-71. Oxford: BAR International Series, 194.

1992 Chavin and the Origins of Andean Civilization. New York: Thames and Hudson.

2003 «Conclusions: cultures of the ecuadorian Formative in their Andean contexts». En: J.S. Raymond y R.L. Burger (eds.) Archaeology of Formative Ecuador, pp. 465-486. Washington D.C.: Dumbarton Oaks Research Library and Collection.

BRAY, Tamara L.

1995 «The Panzaleo puzzle: Non-local pottery in northern highland Ecuador».Journal of Field Archaeology, Vol. 22 (2): 137-156.

CHURCH, Warren

1996 Prehistoric cultural development and interregional interaction in the tropical montane forests of Peru. Tesis de doctorado, Department of Anthropology, Yale University.

CHURCH, Warren y Adriana VON HAGEN

2008 «Chachapoyas: Cultural development at an Andean cloud forest crossroad». En: H. Silverman y W.H. Isbell (eds.) Handbook of South American Archaeology, pp. 903-926. New York: Springer.

CIEZA DE LEÓN, Pedro de

1985 [1553] La crónica del Perú. Segunda parte (El señorío de los Incas). Lima: PUCP.

DeBOER, Warren

2003 "Ceramic assemblage variability in the Formative of Ecuador and Peru». En: J.S. Raymond y R.L. Burger (eds.) Archaeology of Formative Ecuador, pp. 465-486. Washington D.C.: Dumbarton Oaks Research Library and Collection.

ELERA, Carlos

1993 «El complejo cultural Cupisnique: Antecedentes y desarrollo de su ideología religiosa». Senri Ethnological Studies, 37: 229-257.

GENTRY, Alwyn

1988 «Changes in plant community diversity and floristic composition on environmental and geographical gradients». Annals of the Missouri Botanical Garden, 75: 1-34

GUFFROY, Jean

2008 «Cultural boundaries and crossings: Ecuador and Peru». En: H. Silverman y W.H. Isbell (eds.) Handbook of South American Archaeology, pp. 889-902. New York: Springer.

ISBELL, William

1974 «Ecología de la expansión de los Quechua-Hablantes». Revista del Museo Nacional de Antropología y Arqueología, 40: 139-155. 
INOKUCHI, Kinya

2008 «The architecture of Kuntur Wasi: Construction sequence and chronology of a ceremonial center of the Formative period. The Formative period: Recent approaches and evidences. Fifty years of the Japanese archaeological mission and its Contributions». Boletín de Arqueología. PUCP, 12: 219247. Lima: PUCP.

JIJÓN Y CAAMAÑO, Jacinto

1997 Antropología prehispánica del Ecuador. 2nd Edición. Quito: Museo Jacinto Jijón y Caamaño.

JIMÉNEZ DE LA ESPADA, Marcos (ed.)

1897 «Relacion de la gobernacion de Yahuarzongo y Pacamurus». En: M. Jiménez de la Espada (ed.) Relaciones Geográficas de Indias. Tomo IV, Perú: 34-45. Madrid: Ministerio de Fomento.

KAUFFMANN DOIG, Federico

2003 Los Chachapoyas. Moradores ancestrales de los Andes amazónicos peruanos. Lima: Universidad Alas Peruanas.

KOHL, Phillip

2008 «Shared social fields: Evolutionary convergence in prehistory and contemporary practice». American Anthropologist, 110 (4): 495-506.

LARCO, Rafael

1941 Los Cupisniques. Lima: Casa Editora «La Crónica y Variedades» S.A.

LATHRAP, Donald W.

1968 «Aboriginal occupation and changes in river channel on the Central Ucayali, Peru». American Antiquity, 33 (1): 62-79

1970 The Upper Amazon. New York: Thames and Hudson.

1971 The tropical forest and cultural context in Chavin. En: E.P. Benson (ed.) Dumbarton Oaks Conference on Chavin, pp. 73-100. Washington D.C.: Dumbarton Oaks.

LESSER, Alexander

1985 «Social fields and the evolution of society». En: Sidney W. Mintz (ed.) History, Evolution, and the Concept of Culture. Selected Papers por Alexander Lesser, pp. 92- 99. Cambridge: Cambridge University Press.

2007 Chavín. Excavaciones arqueológicas. Lima: Universidad Alas Peruanas.

MIASTA, Jaime

1979 El Alto Amazonas, arqueología de Jaén y San Ignacio, Perú. Lima: Seminario de Historia Rural Andina, UNMSM.

MOHR-CHAVEZ, Karen

1977 Marcavalle: The ceramics from an Early Horizon site in the valley of Cusco, Peru, and implications for south highland socioeconomic interaction. Tesis de doctorado Departmentof Anthropology, University of Pennsylvania.

MORALES, Daniel

1992 «Chambira: Alfareros tempranos de la Amazonia peruana». En: D. Bonavia (ed.) Estudios de Arqueología Peruana, pp. 149-176. Lima: Fomciencias.

2005 «El dios felino en Pacopampa». Arqueología y Sociedad, 16: 215-290. Lima: Museo de Arqueología y Antropología, UNMSM.

NESBITT, Jason

2012 Excavations at Caballo Muerto: An investigation into the origins of the Cupisnique Culture. Tesis de doctorado inédito, Department of Anthropology, Yale University.

NILES, Susan

1999 The Shape of Inca History: Narrative and architecture in an Andean Empire. Iowa City: University of Iowa Press.

OLIVERA, Quirino

1998 «Evidencias arqueológicas del periodo Formativo en la cuenca baja del río Utcubamba y Chinchipe». Boletín de Arqueología PUCP, 2: 105-112. Lima: PUCP. 
PAUKETAT, Timothy

2001 «Practice and history in archaeology: An emerging paradigm». Anthropological Theory, 1(1): 73-98.

2007 Chiefdoms and Other Archaeological Delusions. Walnut Creek, CA: Alta Mira Press.

PAZ, Gladys

2011 Análisis Malacógico: Proyecto de investigación arqueologico Huayurco: Bellavista,Jaén-Huarango, San Ignacio Cajamarca (informe arqueológico inédito)

PULGAR, Javier

1972 Las ocho regiones naturales del Perú. Lima: Editorial Universo.

RAYMOND, J. Scott

1988 «A view from the tropical forest». En: R.W. Keatings (ed.) Peruvian Prehistory, pp. 279-300. Cambridge: Cambridge University Press.

REICHEL-DOLMATOFF, Gerardo

1975 The Shaman and the Jaguar: A study of narcotic drugs among the Indians of Colombia. $1^{\text {st }}$ Ed. Philadelphia: Temple University Press.

ROE, Peter

1982 The Cosmic Zygote: Cosmology in the Amazon basin. New Brunswick: Rutgers University Press.

ROJAS, Pedro

1961 Informe preliminar de la exploración arqueológica al Alto Marañon. Exploracion arqueológica al Alto Marañon, Tomo III. Auspiciada por el Museo Nacional de Antropologia y Arqueologia de Lima y Financiada por La Wenner-Gren Foundation de New York.

1985 «La 'Huaca' Huayurco, Jaén». En: F. Silva, W. Espinoza y R. Ravines (eds.) Historia de Cajamarca I. Arqueología, pp. 181-186. Cajamarca: Instituto Nacional de Cultura.

RUIZ, Arturo

2010 Amazonas: Arqueología e Historia. Lima: Universidad Alas Peruanas.

SAKAI, Masato y Juan José MARTÍNEZ

2008 «Excavations at the Templete de Limoncarro in the Lower valley of Jequetepeque. The Formative period: Recent approaches and evidences. Fifty years of the Japanese archaeological mission and its Contributions». Boletín de Arqueología. PUCP, 12: 171-202. Lima: PUCP.

SANDOVAL, Wilfredo

2012 «Descubren en Bagua los primeros murales amazónicos de América». El Comercio: 12a: 12 de Marzo. Lima. Disponible en <http://www.scribd.com/doc/85047560/Descubren-en- Bagua primeros-murales-amazonicos-de-America>. [Acceso el 11 de octubre de 2012].

SCHJELLERUP, Inge

2005 Incas y españoles en la conquista de los Chachapoya. Lima: PCUP e IFEA.

SHADY, Ruth

1973 La arqueología de la cuenca inferior del Utcubamba. Tesis (Dr.) Programa Académico de Antropología y Arqueología, UNMSM.

1987 «Tradición y cambio en las sociedades formativas de Bagua, Amazonas, Perú». Revista Andina, 5(2): 457-488.

1999 «Sociedades formativas de Bagua-Jaén y sus relaciones andinas y amazónicas». En: P. LedergerberCrespo (ed.) Formativo Sudamericano, pp. 201-211. Quito: Abya-Yala

SHADY, Ruth y Hermilio ROSAS

1979 «El complejo Bagua y el sistema desde establecimiento durante el Formativo en la Sierra Norte del Perú». Ñawpa Pacha, 10: 109-154, Lima.

STAHL, Peter

1986 «Hallucinatory imagery and the origin of early South American figurine art». World Archaeology, 18 (1): $134-150$

STEWARD, Julian

1948 «The tribes of the Montana: An introduction». En:J. Steward (ed.) Handbook of South American Indians, Volume 3. The Tropical Forest Tribes. Bulletin 143, pp. 507-533. Washington, D.C: Smithsonian Institution. 
STONE, Rebecca

2011 The Jaguar Within: Shamanic trance in ancient central and South American Art. Austin: University of Texas Press.

TAYLOR, Anne Christine

1999 «The western margins of Amazonia from the early sixteenth to the early nineteenth century». En: F. Salomon y S. Schwartz (eds.) The Cambridge History of the Native Peoples of the Americas. Volume 3: South America. Parte 1, pp. 188-256. Cambridge: Cambridge University Press.

TELLO, Julio C.

1960 Chavín: Cultura matriz de la civilización andina. Lima: Archivo Julio C. Tello, UNMSM.

TERADA, Kazuo y Yoshi ONUKI

1982 Excavations at Huacaloma in the Cajamarca Valley, Peru, 1979. Tokyo: University of Tokyo Press.

TOYNE, J. Marla

2012 Final report of the human osteological analysis from the Huayurco Archaeological Project, Jaén Peru (informe arqueológico inédito). 